\title{
1 Effects of ultraviolet radiation on mercury isotope fractionation 2 during photo-reduction for inorganic and organic mercury species
}

3

\author{
Carla H. Rose ${ }^{1}$, Sanghamitra Ghosh ${ }^{2}$, Joel D. Blum ${ }^{3}$ and Bridget A. Bergquist ${ }^{1}$
}

${ }^{1}$ University of Toronto, Department of Geology, Earth Science Centre, 22 Russell Street, Toronto, ON M6R 2P2, Canada, c.hendrika.rose@gmail.com, bergquist@es.utoronto.ca

${ }^{2}$ Indian Institute of Technology, Bhubaneswar, School of Earth, Ocean and Climate Sciences, Bhubaneswar, Odisha, India, sanghamitrag@gmail.com

${ }^{3}$ University of Michigan, Department of Earth and Environmental Sciences, 1100 North University Ave Ann Arbor, MI 48109, jdblum@umich.edu

\section{Abstract}

Photo-reduction of mercury $(\mathrm{Hg})$ is an important mechanism for removal of both $\mathrm{Hg}^{2+}$ species and monomethylmercury (MMHg) from surface waters. Large mass independent fractionation (MIF) signatures of $\mathrm{Hg}$ isotopes preserved in natural samples is thought to reflect MIF produced during aqueous photo-reduction by the magnetic isotope effect (MIE). Recently, $\mathrm{Hg}$ MIF signatures in natural samples are being used to quantify photochemical reduction in aquatic systems. However, the fractionation factors used are from laboratory experiments that did not investigate many of the environmental parameters that may affect MIF during photoreduction. In this study, the effects of different regions of the solar spectrum on the expression of MIF caused by the MIE during $\mathrm{Hg}^{2+}$ and $\mathrm{MMHg}$ photo-reduction were investigated to assess how the type of radiation affects the extent and signature of MIF. Photo-reduction in the presence of DOM was carried out through exposure to the full natural solar spectrum unfiltered, with the ultraviolet B (UVB; 290-320 nm) portion removed and with both the UVB and the ultraviolet A (UVA; 320-400 nm) removed. There is a clear relationship between the expression and magnitude of MIF and the energy of incident radiation for both $\mathrm{Hg}^{2+}$ and $\mathrm{MMHg}$ photo-reduction. The experiments indicate that MIF produced during photo-reduction 
of $\mathrm{Hg}^{2+}$ is significantly influenced by both UVB and UVA radiation. For $\mathrm{MMHg}$ photodemethylation, however, UVB radiation is mostly responsible for the MIF with minor contributions from UVA. Overall, there is a lack of correlation between the observed MIF and total photo-reduction in the experiments conducted in this study, which indicates that indirect and other non-MIF producing pathways of photo-reduction are the dominant pathways by which $\mathrm{Hg}$ species are being photo-reduced. Extrapolating these experimental results to natural systems is difficult as the experiments were not performed at realistic $\mathrm{Hg} / \mathrm{DOM}$ ratios and the distribution of ligands that $\mathrm{Hg}$ is bound to in the experiments likely differs from natural systems. However, the strong relationship between MIF and energy of incident radiation in this study supports Hg MIF signatures as promising tools for helping to quantify photochemical cycling of mercury, but this study also highlights the need to understand the link between MIF and total photo-reduction before this tool can be fully utilized.

Keywords: mercury, stable mercury isotopes, monomethylmercury, photo-reduction, photodemethylation, mass-independent fractionation, Rayleigh fractionation factors

\section{Introduction}

Mercury is toxic in all of its forms, but it is monomethylmerucy (MMHg) that bioaccumulates in aquatic food webs and is the major pathway for human and wildlife exposure through fish consumption (see review: Fitzgerald and Lamborg, 2014). Mercury is introduced to the environment from anthropogenic activities such as combustion of fossil fuels, waste incineration, mining and industrial manufacturing, and also from natural emissions including volcanoes, hydrothermal activity and biomass burning. Once in the environment, $\mathrm{Hg}$ goes through complex redox, biological and phase transformations and is frequently re-emitted to the atmosphere after deposition to soil and water surfaces. Many of its pathways and transformations in the environment are still not completely understood and are poorly quantified (see review: Fitzgerald and Lamborg, 2014). Recent advances in cold vapor multicollector inductively coupled plasma mass spectrometry (CV-MC-ICP-MS, Lauretta et al., 2001) allow precise determination of the relative abundances of the stable isotopes of $\mathrm{Hg}$ and has proved to be a useful tool in understanding sources and transformations of $\mathrm{Hg}$ in nature (see review: Blum, 2012). Mercury is unique in that it not only displays mass-dependent 
fractionation (MDF), but also large mass-independent fractionation (MIF) (Bergquist and

67 Blum, 2007). The reported range of isotopic values in natural materials is now up to $10 \%$ for both MDF and for MIF of the odd isotopes (Blum, 2012). While many environmental transformations induce MDF (see reviews: Bergquist and Blum, 2009; Sonke, 2011; Blum, 2012), the only processes reported to result in large MIF ( $>0.5 \%$ ) are photochemical reduction of $\mathrm{Hg}^{2+}$ and MMHg (Bergquist and Blum, 2007; Malinovsky et al., 2010; Sherman et al., 2010; Zheng and Hintelmann, 2009; Zheng and Hintelmann, 2009, 2010a). Constraining the processes that cause MIF signatures and the environmental factors that affect them is necessary if MIF signatures are to be useful for tracing and quantifying specific $\mathrm{Hg}$ sources and transformations.

Two mechanisms are currently thought to produce odd isotope mass-independent anomalies in $\mathrm{Hg}$ isotopes: the nuclear volume effect (NVE) and the magnetic isotope effect (MIE). Of these, it is thought that MIE is responsible for the large MIF observed in photochemical reactions (Bergquist and Blum, 2007; Malinovsky et al., 2010). This effect is a result of hyperfine coupling interactions (HFI) between the magnetic moments of odd nuclei (even isotopes have nuclear magnetic moments of zero) and the spin magnetic moments of unpaired electrons. The HFI are small and have no effect on the equilibrium characteristics of chemical systems (Turro, 1983; Bigeleisen, 1996; Engel and Reid, 2006), but can produce a paramagnetic intermediates such as radical pairs are involved. The MIE is observed when the magnetic and non-magnetic nuclei are distributed differently among the reaction products (see reviews: Turro, 1983; Buchachenko, 2011). For example, if photolysis of a mercury compound generates radical pairs in a triplet state, they are spin-forbidden from recombining. The unpaired electron of an odd isotope, ${ }^{199} \mathrm{Hg}$ or ${ }^{201} \mathrm{Hg}$, can undergo spin conversion faster to a singlet state allowing the odd nuclei to preferentially recombine and be enriched in the starting material (ex. Bergquist and Blum, 2007; Zheng and Hintelmann, 2009; Malinovsky et al., 2010). Alternatively, if photolysis conditions result in a singlet state radical pair, the odd nuclei can preferentially undergo spin conversion to a triplet state and be enriched in the product species (ex. Buchachenko et al., 2007; Zheng and Hintelmann, 2010a). The MIE to explain MIF is frequently adopted by investigators to explain MIF during the photochemical reduction of aqueous $\mathrm{Hg}$ species in the presence of dissolved organic matter (DOM) and MIF observed in 
natural samples. However, the only direct proof of the MIE mechanism during photochemical reduction of $\mathrm{Hg}$ so far has been by Malinovsky et al. (2010). The authors report suppression of MIF by addition of radical scavengers during photodemethylation of MMHg in solutions with ascorbic acid and with ammonia, and attribute it to suppression of radical pair formation or to scavenging of the radical pair during decomposition.

Photo-reduction of $\mathrm{Hg}$ species is known to be a significant process for removal of both $\mathrm{Hg}^{2+}$ species and MMHg in surface waters (Amyot et al., 1994, 1997; Sellers et al., 1996; Poulain et al., 2004; O’Driscoll et al., 2006; Hammerschmidt and Fitzgerald, 2006; Lehnherr \& St. Louis, 2009; Black et al., 2012; Kim and Zoh, 2013; Fernańdez-Goḿez et al., 2013; Tai et al., 2014; Qian et al., 2013), although the specific mechanisms operating in natural environments are elusive, in particular for $\mathrm{MMHg}$. $\mathrm{Hg}^{2+}$ compounds can photolyse readily at very short wavelengths, generally due to ligand-to-metal charge transfer (LMCT; see review, Kunkely et al., 1997), and there have also been laboratory demonstrations of $\mathrm{Hg}^{2+}$ bonds photolysing at naturally available wavelengths (ex. Kern, 1952; Zepp et al., 1973; Kunkely and Vogler, 2001; Horvath et al. 2004). More work is needed to establish whether the C-Hg bond in MMHg can be excited by wavelengths longer than $290 \mathrm{~nm}$, although this is predicted to be possible for certain species (ex. Tossell, 1998). Photo-reduction of $\mathrm{Hg}$ compounds by radical species that are both oxidizing ( $\cdot \mathrm{OH}$, Chen et al., 2003, Kim and Zoh, 2013 and ${ }^{1} \mathrm{O}_{2}$, Zhang and Hsu-Kim, 2010) and reducing ( $\mathrm{H}^{*}$ and $\mathrm{CO} \cdot$, Zheng et al., 2005, and Han et al., 2007) are also proposed. There are many environmental factors known to affect $\mathrm{Hg}^{2+}$ and $\mathrm{MMHg}$ photoreduction rates in nature. Light intensity and frequency, with higher rates associated with shorter wavelengths, is thought to be a major control over photo-reduction rates (Krabbenhoft et al., 2002; Hammerschmidt \& Fitzgerald, 2006; Lehnheer \& St. Louis, 2009; Li et al., 2010; Black et al., 2012; Kim and Zoh, 2013; Fernańdez-Gomez et al., 2013). The DOM type and amount (Xia et al., 1998; Ravichandran, 2004; O’Driscoll et al., 2004; Garcia et al., 2005; Zhang and Kim, 2010; Tai et al., 2014; Qian et al., 2014) and the presence of other metals such as Fe in solution (Zhang and Lindberg, 2001; Kim and Zoh, 2013) can also be important variables.

Because it is thought that $\mathrm{Hg}$ MIF in natural samples is dominantly caused by photoreduction, it was proposed that $\mathrm{Hg}$ MIF signatures could be used to quantify photochemical reduction in nature and to put constraints on the $\mathrm{Hg}$ biogeochemical cycle (Bergquist and Blum, 
2007; Sonke, 2011). For example, Bergquist and Blum (2007) postulated that MIF signatures in fish were due to photo-demethylation of MMHg in the water column prior to incorporation in the food web. This was largely based on $>90 \%$ of $\mathrm{Hg}$ in fish muscle being MMHg (Harris et al, 2003) and on the similar extents and ratios of MIF $\left(\Delta^{199} \mathrm{Hg} / \Delta{ }^{201} \mathrm{Hg}\right)$ for MMHg photodemethylation experiments and for freshwater fish muscle $\left(\Delta^{199} \mathrm{Hg} / \Delta{ }^{201} \mathrm{Hg}\right.$ of $\sim 1.3$ for both $)$. Photo-reduction of $\mathrm{Hg}^{2+}$ yielded a significantly different ratio ( 1.0). Using experimentally determined fractionation factors, and MIF signatures preserved in freshwater fish, the authors estimated the corresponding photodemethylation of bulk MMHg for several locations. This approach has been used several times subsequently (Bergquist and Blum, 2007; Jackson et al., 2008; Gantner et al., 2009; Laffont et al., 2009; Gartner et al., 2009; Senn et al., 2010; Gehrke et al., 2011; Sherman and Blum, 2013; Blum et al., 2013; Tsui et al., 2014; Kwon et al., 2014) even though the only published fractionation factors for photo-demethylation with natural dissolved organic matter (DOM) were obtained at unrealistic MMHg to DOM ratios and with only one type of organic matter (Bergquist and Blum, 2007). There is only limited information on how environmental variables will affect fractionation factors. Zheng and Hintelman (2009, 2010a) demonstrated that DOM type and amount significantly affected the expression of $\mathrm{Hg}^{2+} \mathrm{MIF}$ during photo-reduction and the same has recently been demonstrated for $\mathrm{MMHg}$ photodemethylation (Chandan et al., 2014). The effects of type and amount of solar radiation as well as aqueous matrix composition remains unexplored for both $\mathrm{Hg}^{2+}$ and MMHg. Sonke (2011) presented a global model of mass independent $\mathrm{Hg}$ isotopes, but conceded that many fractionation factors were poorly known if at all and that much more work is needed to constrain MIF of $\mathrm{Hg}$ before a model could truly represent the $\mathrm{Hg}$ cycle.

The primary objective of this study was to assess the effect of limiting the energy spectrum of electromagnetic radiation on the expression of MIF during photo-reduction of both inorganic and organic mercury species. Photo-reduction of both $\mathrm{Hg}^{2+}$ and $\mathrm{MMHg}$ in the presence of DOM was carried out through exposure to (1) the full natural solar spectrum unfiltered, (2) with the ultraviolet B (UVB; 290-320 nm) portion removed and (3) with both the UVB and the ultraviolet A (UVA; 320-400 nm) removed. As the shorter wavelengths were removed, it was hypothesized that radiation remaining would be less effective at producing radical species. The MIE cannot be expressed in the absence of unpaired electrons, therefore we expected MIF to be suppressed as higher energy radiation was screened from the reaction vessels. Additional goals 
159

160

161

162

163

164

165

166

167

168

169

170

171

172

173

174

175

176

177

178

179

180

181

182

183

184

185

186

187

188

189

were to assess how MIF is related to total photo-reduction and whether MIF can be used to quantify photo-reduction.

\section{Materials and methods}

\subsection{Materials}

All acids were of trace metal grade and water used was deionized Millipore (18 $\mathrm{M} \Omega$ ). All sample containers and analytical vials were glass and were cleaned with both $10 \% \mathrm{HCl}$ and $2 \% \mathrm{BrCl}$ followed by 5 rinses with $18 \mathrm{M} \Omega$ water.

\subsection{Photo-reduction experiments}

Two sets of three simultaneous photochemical reduction experiments each were carried out using a $\mathrm{Hg}\left(\mathrm{NO}_{3}\right)_{2}$ standard (J.T. Baker), and two sets of three simultaneous photochemical reduction experiments each were carried out using a $\mathrm{CH}_{3} \mathrm{HgCl}$ standard (Alfa Aesar). Photoreduction took place under natural sunlight in Toronto, Canada $\left(43^{\circ} \mathrm{N}, 79^{\circ} \mathrm{W}\right)$. Initial sets for each species were carried out in July, 2009, and replicate sets in September, 2009. Aqueous solutions of $2 \mathrm{mg} / \mathrm{L}$ Suwannee River Fulvic Acid Standard (International Humic Substance Society 1S101F; http://ihss.gatech.edu/ihss2/ ) were prepared in glass bottles, sampled to verify negligible mercury content, spiked to achieve a final concentration of $\mathrm{Hg}$ of approximately 30 $\mu \mathrm{g} / \mathrm{L}$ for the $\mathrm{Hg}^{2+}$ experiments (using the $\mathrm{Hg}\left(\mathrm{NO}_{3}\right)_{2}$ standard) and approximately $25 \mu \mathrm{g} / \mathrm{L}$ for the $\mathrm{MMHg}$ experiments (using the $\mathrm{CH}_{3} \mathrm{HgCl}$ standard), sub-sampled to determine initial $\mathrm{Hg}$ isotopic composition, and allowed to equilibrate overnight wrapped in aluminum foil. Experimental $\mathrm{Hg}$ concentrations were four to five orders of magnitude higher than in typical freshwaters, but were chosen to facilitate high precision $\mathrm{Hg}$ isotope analyses of the run products. The morning following preparation, the foil-wrapped solutions were transferred to a 1-L quartz reactor (as in Bergquist and Blum 2007, SI) and promptly covered with the UV filters where appropriate. Mercury vapor, $\mathrm{Hg}^{0}$, was continuously sparged from solutions with ambient air pulled through a $0.2 \mu \mathrm{m}$ filter and gold trap to remove particles and $\mathrm{Hg}$. The reservoir was sub-sampled immediately after set up and at intervals over the day as the reactions progressed. Sub-samples 
190

191

192

193

194

195

196

197

198

199

200

201

202

203

204

205

206

207

208

209

210

211

212

213

214

215

216

217

218

219

220

were immediately preserved by spiking with concentrated $\mathrm{BrCl}$ to achieve a sample $\mathrm{BrCl}$ concentration of $2.5 \%$.

UV light filters were boxes closed on five sides that were placed over the quartz reactors. Mylar sheets screened the UVB portion of the electromagnetic spectrum (93-95\%), some of the UVA spectrum (43-45\%), and a small amount of the visible spectrum (19-22\%). Acrylic sheets covered with a $3 \mathrm{M}$ Scotchshield (Ultra S150) window film screened the UVB (96\%) the UVA $(98 \%)$ portions of the spectrum and a small amount of the visible spectrum when the sun was not directly overhead. Around mid-day, the intensity of visible light was higher under the acrylic box (by $30 \%$ or more) than the intensity of visible light under direct solar radiation. Measurements of the light reaching each reactor were taken with a Solar Light PMA2200 Radiometer fitted with detectors specific to the three spectral regions of interest: UVB (PMA2106), UVA (PMA2110) and Visible (PMA2130). Dark control experiments for $\mathrm{Hg}^{2+}$ and $\mathrm{MMHg}$ were performed in the laboratory with the same procedure except that the quartz reactors were covered with aluminum foil at all times.

Since the $\mathrm{Hg}$ speciation was not determined during the experiments as the reaction progressed in the reservoir, it was assumed that $\mathrm{MMHg}$ photo-degraded to $\mathrm{Hg}^{0}$ without significant $\mathrm{Hg}^{2+}$ contamination in the reservoir. This is supported by high and consistent $\Delta^{199} \mathrm{Hg} / \Delta^{201} \mathrm{Hg}$ ratios for the MMHg experiments in this study $(1.33 \pm 0.14,2 \mathrm{SE})$ along with other studies (Bergquist and Blum, 2007; Chandan et al., 2014), which likely would be significantly lowered if significant amounts of $\mathrm{Hg}^{2+}$ were present in the reservoir undergoing photo-reduction with a ratio of $\sim 1$ (for example, $0.98 \pm 0.04$ (2SE) in this study).

\subsection{Hg concentration and isotope analysis}

Concentrations of $\mathrm{Hg}$ in the aqueous samples were measured using a Tekran 2600 Cold Vapor Atomic Fluorescence Spectrometer (CVAFS) following a modification of US EPA Method 1631, Revision E. The standard reference material NIST1641d was used to monitor accuracy and precision, and the error for $\mathrm{Hg}$ concentrations was $\pm 5 \%$ (1SD). To avoid matrix effects during isotopic analysis, $\mathrm{Hg}$ was transferred from sample matrices to an aqueous acidic trapping solution of $10 \%$ (wt) $\mathrm{H}_{2} \mathrm{SO}_{4}$ and $1 \%$ (wt) $\mathrm{KMnO}_{4}$ by $\mathrm{SnCl}_{2}$ reduction, sparging and trapping. The aqueous acidic trapping solution was then reduced with $\mathrm{SnCl}_{2}$ online and $\mathrm{Hg}^{0}$ was 
221 separated using a frosted glass tip gas-liquid separator. Inter-sample blanks were $\sim 0.25 \%$ of 222 sample concentrations. Process standards using NIST 3133 reference mercury solution 223 (concentration- and matrix-matched to samples) were run routinely at the beginning of each 224 session and then throughout the day as needed. Sample recoveries after matrix transfer were 225 always greater than $90 \%$ and usually greater than 95\%. Method replicates were achieved by 226 processing R0 (sampled before Hg-DOM equilibration) from each of the three experiments from 227 both sets.

228 Isotopic compositions were measured on a $\mathrm{Nu}$ Instruments multiple collector inductively 229 coupled plasma mass spectrometer (MC-ICP-MS) at the Department of Earth and Environmental Sciences, University of Michigan. Samples were introduced to the plasma by the online reduction cold vapor generation technique (Lauretta et al., 2001). Instrumental mass bias was corrected with a thallium internal standard (NIST 997; reported ${ }^{205} \mathrm{Tl} /{ }^{203} \mathrm{Tl}$ ratio of 2.38714 ) and through matrix and concentration matched sample standard bracketing (SSB; NIST SRM 3133), as recommended in Blum and Bergquist (2007). The sample matrix $\left(1 \% \mathrm{KMnO}_{4}\right.$ in $\left.10 \% \mathrm{H}_{2} \mathrm{SO}_{4}\right)$ was pre-reduced with $\mathrm{NH}_{2} \mathrm{OH}$ a minimum of one hour before cold vapor generation. On-peak zero corrections were applied to all $\mathrm{Hg}$ and $\mathrm{Pb}$ masses by measuring a matrix matched blank solution prior to each sample after 10 to 12 minutes of washout. Blank correction on the $\mathrm{Tl}$ masses was not possible because $\mathrm{Tl}$ was continuously streamed throughout the analytical sessions. Isobaric interference of ${ }^{204} \mathrm{~Pb}$ on ${ }^{204} \mathrm{Hg}$ was corrected by monitoring ${ }^{206} \mathrm{~Pb}$, but was always negligible. The Faraday cups were configured to collect masses of 196, 198, 199, 200, 201, 202, 203, 204, 205 and 206 atomic mass units.

Isotopic compositions are reported in delta notation as the permil (\%o) deviation from the bracketing NIST SRM 3133 standards after blank and Tl corrections. It is determined through

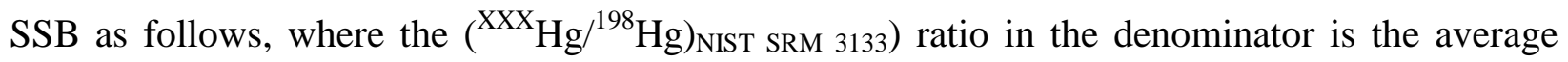
ratio of the bracketing standards run prior to and after the sample:

$\left.\mathrm{Hg}=\left[(\mathrm{Hg} / \mathrm{Hg})_{\text {sample }} /\left(\mathrm{Hg} /{ }^{1} \mathrm{Hg}\right)_{\text {NIST3133 std }}\right)-1\right] \times 1000$

247 where $\mathrm{XXX}$ is the mass the $\mathrm{Hg}$ isotope of interest from 198 to $204 \mathrm{amu}$. Mass-independent 248 fractionation is reported using capital delta notation $\left(\Delta^{\mathrm{XXX}} \mathrm{Hg}\right)$ and is the deviation in isotope 249 ratios from the theoretical values predicted by MDF, also in units of permil (\%). The theoretical 250 isotope ratios are determined using the ${ }^{202} \mathrm{Hg} /{ }^{198} \mathrm{Hg}$ ratio (i.e. $\delta^{202} \mathrm{Hg}$ ) and applying the kinetic 
251 mass-dependent fractionation law derived by Bigeleisen (1949) and reviewed by Young et al.

252 (2002) as follows:

$253 \Delta \Delta^{199} \mathrm{Hg}=1000 \times\left\{\ln \left[\delta^{199} \mathrm{Hg} / 1000+1\right]-0.2520 \times \ln \left[\delta^{202} \mathrm{Hg} / 1000+1\right]\right\}$

$254 \Delta^{200} \mathrm{Hg}=1000 \times\left\{\ln \left[\delta^{200} \mathrm{Hg} / 1000+1\right]-0.5024 \times \ln \left[\delta^{202} \mathrm{Hg} / 1000+1\right]\right\}$

255

$\Delta^{201} \mathrm{Hg}=1000 \times\left\{\ln \left[\delta^{201} \mathrm{Hg} / 1000+1\right]-0.7520 \times \ln \left[\delta^{202} \mathrm{Hg} / 1000+1\right]\right\}$

$256 \Delta^{204} \mathrm{Hg}=1000 \times\left\{\ln \left[\delta^{204} \mathrm{Hg} / 1000+1\right]-1.493 \times \ln \left[\delta^{202} \mathrm{Hg} / 1000+1\right]\right\}$.

257

External reproducibility was monitored with a secondary standard, UM-Almadén, of different isotopic composition than the bracketing standard. The data presented here were produced over 8 analytical sessions (October 2009 -July 2010). The mean Almadén values for the October through January sessions were $\delta^{202} \mathrm{Hg}=-0.58 \pm 0.13 \%$ and $\Delta^{199} \mathrm{Hg}=0.00 \pm 0.07 \%$ ( $2 \mathrm{SD}, \mathrm{n}=12$ ). The mean Almadén values for the June and July sessions were $\delta^{202} \mathrm{Hg}=-0.58 \pm$ $0.09 \%$ and $\Delta^{199} \mathrm{Hg}=-0.02 \pm 0.07 \%$ o $(2 \mathrm{SD}, \mathrm{n}=20)$.

\subsection{Estimation of fractionation factors}

265

266

Photo-reduction of both $\mathrm{Hg}^{2+}$ and $\mathrm{MMHg}$ appeared to follow a Rayleigh distillation

267

268 model. Thus, kinetic fractionation factors were determined from the results of our experiments using the form of the Rayleigh distillation equation outlined by Mariotti et al., 1981:

$\left(10^{-3} \varepsilon_{\mathrm{p} / \mathrm{r}}\right) \ln (\mathrm{f})=\ln \left(10^{-3} \delta^{\mathrm{x}} \mathrm{Hg}_{\mathrm{t}}+1\right) / \ln \left(10^{-3} \delta^{\mathrm{x}} \mathrm{Hg}_{0}+1\right)$

270

271

272

273

274

275

276

277

278

279

280

where, $\varepsilon_{\mathrm{p} / \mathrm{r}}$ is the enrichment factor (\%o), which is related to the fractionation factor using $\alpha_{\mathrm{p} / \mathrm{r}}=1$ $+\left(\varepsilon_{\mathrm{p} / \mathrm{r}} / 1000\right), \mathrm{f}$ is the fraction of $\mathrm{MMHg}$ remaining in the reservoir, $\delta^{\mathrm{x}} \mathrm{Hg}_{0}$ is the initial isotopic composition of $\mathrm{Hg}$ where $\mathrm{x}={ }^{199} \mathrm{Hg}$ to ${ }^{204} \mathrm{Hg}$, and $\delta^{\mathrm{x}} \mathrm{Hg}_{\mathrm{t}}$ is the isotopic composition of $\mathrm{Hg}$ at time (t) where $\mathrm{x}={ }^{199} \mathrm{Hg}$ to ${ }^{204} \mathrm{Hg} . \Delta^{199} \mathrm{Hg}_{0}$ and $\Delta^{199} \mathrm{Hg}_{\mathrm{t}}$ were substituted for $\delta^{\mathrm{x}} \mathrm{Hg}_{0}$ and $\delta^{\mathrm{x}} \mathrm{Hg}_{\mathrm{t}}$ respectively to estimate $\alpha_{\Delta 199}$. The slope of the best linear fit of the relation $\ln \left(\Delta^{199} \mathrm{Hg}\right)$ or $\ln$ $\left(\delta^{202} \mathrm{Hg}\right)$ as a function of $\ln (\mathrm{f})$ represents the enrichment factor $(\varepsilon \mathrm{p} / \mathrm{r})$, which was used to calculate kinetic fractionation factors $\alpha_{\delta 202}$ and $\alpha_{\Delta 199}$. The uncertainty in $\alpha_{\delta 202}$ and $\alpha_{\Delta 199}$ was estimated using the $2 \mathrm{SE}$ of the slope.

\section{Results}




\subsection{Light intensities}

Quartz reactors containing either $\mathrm{Hg}^{2+}$ or $\mathrm{MMHg}$ in aqueous solutions with dissolved organic matter were simultaneously exposed to three different light regimes. Initial sets of three replicates were carried out on July $19^{\text {th }}(\mathrm{MMHg})$ and July $30^{\text {th }}\left(\mathrm{Hg}^{2=}\right), 2009$, and additional replicate sets of three were carried out on September $1^{\text {st }}(\mathrm{MMHg})$ and September $3^{\text {rd }}\left(\mathrm{Hg}^{2+}\right)$, 2009. Ultraviolet intensities in September were generally lower (Table S1 in the Supporting Information, SI). For example, the maximum UVB intensities recorded near solar noon (approximately $1 \mathrm{pm}$ ) in September were $\sim 30 \%$ lower than the corresponding July intensities. UVA intensities were $20 \%$ lower in September than in July. Visible waveband intensities were not significantly different between September and July. Technical difficulties lead to the exposure of the September $\mathrm{Hg}^{2+}$ no UV experiment to the full solar spectrum (i.e., the filter box had to be removed for more than an hour); thus, this experiment was compromised and the data is not presented.

\section{2. $\mathrm{Hg}^{2+}$ and MMHg concentration loss during photo-reduction}

The amount of $\mathrm{Hg}^{2+}$ or $\mathrm{MMHg}$ lost via photo-reduction was estimated from the decreasing concentration of $\mathrm{Hg}$ in the substrate reservoir over time (Figure 1). Experimental ratios of $\mathrm{Hg}$ :DOM were far higher than are typically found in nature. This was necessary to allow for high precision isotopic analyses, but meant that chemical conditions, such as the profile of Hg-binding sites, are not typical of natural freshwaters and so kinetic reduction rates from this study are not directly applicable to natural systems.

In July, $\mathrm{Hg}^{2+}$ showed similar maximum losses of $80 \%$ in both the experiment exposed to full sun and the experiment with UVB blocked (Figure 1a). Blocking all UV suppressed most of the photo-reduction (only 10\% loss). Maximum September loss (70\%) was in the full spectrum experiment and blocking of UVB resulted in approximately $40 \%$ loss. In the September $\mathrm{Hg}^{2+}$ experiment with UVB removed (Figure 1b), the lowest reservoir $\mathrm{Hg}$ concentrations are recorded after approximately four hours and are followed by small concentration increases. This is likely a result of reservoir evaporation, as water vapor would have been pumped out of the reactor headspace along with the $\mathrm{Hg}^{0}$. It is likely that the UV 
312 filtering boxes increased the ambient temperature compared to the uncovered, full sun 313 experiment but the temperature contrast between experiments covered and uncovered was not monitored. Dark control experiments were carried out in the laboratory with the $\mathrm{Hg}^{2+}$-organic matter solution shielded with aluminum foil at all times. They showed no detectable losses after 8.5 hours of sparging with $\mathrm{Hg}$-free air (Figure 1a). Thus, we conclude that $\mathrm{Hg}$ loss due to nonphotochemical reduction during the 6-7 hour light experiments was negligible.

In the July MMHg photoexperiments, neither blocking the UVB waveband only nor blocking all UV radiation had a significant effect on the total amount of $\mathrm{MMHg}$ lost (Figure 1c). All three experiments showed losses of approximately $20 \%$ after seven hours of exposure. In September, overall concentration losses were smaller. The experiments exposed to full sun and to UVA lost approximately 10\% (Figure 1d), but the experiment blocking both UVB and UVA appears to have experienced less photo-degradtion (4\%) than its full spectrum counterpart. The smaller losses observed in September might be due to the lower intensity of sunlight in September (see Table S1). The uncertainty in the $\mathrm{Hg}$ concentration measurements $( \pm 5 \%)$ makes it difficult to determine whether loss in the September no UV trial is indeed significantly lower. The MMHg control experiment carried out under foil in the laboratory showed no detectable losses after 8.5 hours of sparging with $\mathrm{Hg}$-free air. We therefore conclude that any losses due to non-photochemical reduction during the 6-7 hour UV filtration experiments were negligible.

\subsection{Mass Dependent Fractionation of $\mathrm{Hg}$} the heavier isotopes preferentially retained in the reactor/reactant, which is consistent with kinetic isotope fractionation (see Figure 2). $\mathrm{The}_{\mathrm{Hg}^{2+}}$ experiments displayed much larger isotopic enrichment in the reactant, up to $\sim 2 \%$ for $\delta^{202} \mathrm{Hg}$, than the $\mathrm{MMHg}$ experiments, which is consistent with the larger extents of reaction for $\mathrm{Hg}^{2+}$. The $\mathrm{MMHg}$ photo-degradation experiments had maximum enrichments of $\sim 0.3 \%$ for $\delta^{202} \mathrm{Hg}$ at $\sim 20 \%$ loss of $\mathrm{MMHg}$.

\section{1 and 2.}




\subsection{Mass-independent isotope fractionation of $\mathrm{Hg}$}

MIF of $\mathrm{Hg}$ was observed for the odd isotopes only, with ${ }^{199} \mathrm{Hg}$ and ${ }^{201} \mathrm{Hg}$ being preferentially retained in the reactor as observed by Bergquist and Blum (2007) for all experiments displaying MIF. Complete MIF data are displayed in Table S2 and S3 in the SI and summarized in Tables 1 and 2.

In July, the largest $\mathrm{Hg}^{2+} \mathrm{MIF}$ signature was $2.45 \pm 0.14 \%$ (2SE) for $\Delta^{199} \mathrm{Hg}$ in the experiment exposed to full sun. Blocking the UVB waveband reduced MIF significantly by 50 $\pm 10 \%$ at a similar extent of reaction, and blocking all UV radiation suppressed most of the photo-reduction and MIF. Rayleigh models based on estimated MIF fractionation factors for July experiments are shown in Figure 3a. In September, the largest $\mathrm{Hg}^{2+} \mathrm{MIF}$ signature, $0.69 \pm$ 0.14\% (2SE) for $\Delta^{199} \mathrm{Hg}$, was also in the experiment exposed to full sun. Blocking the UVB waveband resulted in a significant decrease of $30 \pm 20 \%$ (Figure $3 \mathrm{~b}$ ) at similar extent of reaction. Rayleigh models based on estimated MIF fractionation factors for July experiments are shown in Figure 3b. As no loss in $\mathrm{Hg}^{2+}$ was observed in the dark control, there was no opportunity for MDF or MIF.

In July, the largest MIF value for the MMHg photo-degradation experiments was $0.55 \pm$ 0.07\% for $\Delta^{199} \mathrm{Hg}$ in the experiment exposed to full sun. Although blocking the UVB and UVA wavebands did not have an appreciable effect on total losses of MMHg through photodegradation, MIF was suppressed in both the UVB-blocked experiment and the UVA\&Bblocked experiment (Figure 4a). In September, the full sun experiment also displayed the largest MIF signature, $0.42 \pm 0.14 \%$ o for $\Delta^{199} \mathrm{Hg}$. MIF was significantly reduced by blocking the UVB waveband with MIF suppressed up to $70 \pm 50 \%$ compared to the full sun experiment at a similar extent of reaction (Figure 4b). The effect of blocking UV on MIF in the September experiments is more difficult to quantify, since photo-degradation was very low in these experiments, but the MIF expressed is lower than the full spectrum experiment. No change in MMHg concentration was observed in the dark control, providing no opportunity for MIF.

\subsection{Relationship between $\Delta^{199} \mathrm{Hg}$ and $\Delta^{201} \mathrm{Hg}$}


$\Delta^{199} \mathrm{Hg} / \Delta^{201} \mathrm{Hg}$ ratios were only calculated and used for samples with MIF greater than 374 or equal to $4 \mathrm{SE}$ of the secondary standard, UM-Almadén; this was 0.07 for $\Delta{ }^{199} \mathrm{Hg}$ and 0.05 for

$375 \Delta^{201} \mathrm{Hg}$. Data that met this criteria are plotted in Figure 6. The $\Delta^{199} \mathrm{Hg} / \Delta^{201} \mathrm{Hg}$ slope was $0.98 \pm$ 376 0.04 (2SE) for the $\mathrm{Hg}^{2+}$ photo-reduction experiments and $1.33 \pm 0.14$ (2SE) for MMHg photo377 demethylation experiments.

4. Discussion

\subsection{Mass Dependent Fractionation}

Despite the extent of MDF being much larger in the $\mathrm{Hg}^{2+}$ compared to the $\mathrm{MMHg}$ photo-reduction experiments due to the larger extents of reaction, $\delta^{202} \mathrm{Hg}$ fractionation factors $\left(\alpha_{\delta 202}\right)$ are similar for all $\mathrm{Hg}^{2+}$ and $\mathrm{MMHg}$ experiments that displayed significant $\mathrm{MDF}$ and range from 0.9977 to 0.9992 . For most of the sets of experiments, there are no systematic variations in $\alpha_{\delta 202}$ with filtering of solar light wavelengths or with the higher UV intensities in July. Only in the $\mathrm{Hg}^{2+}$ July experiments is there larger fractionation for the UVB filtered experiment, $\alpha_{\delta 202}=0.9988 \pm 0.0001(2 \mathrm{SE})$, than for the full sun, $\alpha_{\delta 202}=0.9992 \pm 0.0002$ (2SE). This effect is not observed in September, however, where the mass-dependent fractionation factors of the two experiments are indistinguishable. As noted above, higher temperatures under the UV-filtering boxes in September likely resulted in evaporation and slight increases in concentration towards the end of the experiments, possibly confounding the 394 fractionation factors somewhat.

\subsection{MIE as the cause of large MIF in Hg photo-reduction}

The clear relationship between the magnitude of MIF and the wavelengths of light available for $\mathrm{Hg}^{2+}$ and $\mathrm{MMHg}$ photo-reduction experiments suggests that MIE is the dominant mechanism producing MIF during $\mathrm{Hg}$ photo-reduction. For $\mathrm{Hg}^{2+}$, the largest MIF is observed in the experiments exposed to full sun in both the July and the September experiments. The July experiments were exposed to more intense ultraviolet radiation than the September experiments and show correspondingly larger MIF $\left(\alpha_{\Delta 199}=0.9986 \pm 0.0001,2 \mathrm{SE}\right.$, for July and $0.9993 \pm$ 
0.0001, 2SE, for September). For both sets of experiments, UVB is a large contributor to MIF as its removal reduced MIF by up to $50 \pm 10 \%$ in July and by $30 \pm 20 \%$ in September. UVA seems to contribute significantly as well, but how much it contributes relative to visible radiation is not clear because blocking out both UVA and UVB in July reduced overall photoreduction significantly and it was not possible to measure significant isotope fractionation. Thus, for $\mathrm{Hg}^{2+}$ it appears that both the UVB and UVA spectra are likely to be capable of producing MIF.

For MMHg, the most pronounced MIF is also in the experiments exposed to full sun in both the July and the September experiments. However, there was not a clear difference between July and September in the overall amount of MIF expressed in the full sun $\left(\alpha_{\Delta 199}=\right.$ $0.9977 \pm 0.0011,2 \mathrm{SE}$, for July and $0.9964 \pm 0.0014,2 \mathrm{SE}$, for September). The lower overall extents of reaction and smaller MIF magnitudes result in larger uncertainties in the estimates of fractionation factors. It appears that UVB is the major contributor to MIF during photodegradation of MMHg, even more so than for $\mathrm{Hg}^{2+}$. When UVB is blocked, most of the MIF ceases, although small amounts are still present in experiments exposed to UVA in September suggesting that some MIF occurs due to radiation in the UVA region.

\subsection{Relationship between MIF and photo-reduction of $\mathrm{Hg}^{2+}$ and $\mathrm{MMHg}$}

For both $\mathrm{Hg}^{2+}$ and MMHg, there is no relationship between MIF and overall extent of photo-reduction for the experiments in this study. For example, in the $\mathrm{Hg}^{2+}$ July experiments, removing the UVB wavebands has a clear effect on MIF but no significant effect on total amount of photo-reduction. The same was observed for the July MMHg photo-degradation experiments where blocking the UVB waveband largely or completely suppressed MIF, but the amount of total photo-degradation was not significantly affected. This indicates that there are multiple pathways for photo-reduction and not all of them produce MIF in our experiments. As discussed in more detail in section 4.5 , the results from the experiments in this study should not be extrapolated to natural systems as the experiments were not performed at realistic $\mathrm{Hg} / \mathrm{DOM}$ ratios and the distribution of ligands that $\mathrm{Hg}$ is bound to in the experiments likely differs from natural systems. Different Hg-ligand species may have different sensitivities to the energy of radiation. However, the strong relationship between MIF and energy of incident radiation in 
this study supports $\mathrm{Hg}$ MIF signatures as promising tools for helping to quantify photochemical cycling of $\mathrm{Hg}$. From our experiments, it is evident that the higher energy wavelengths (UVA and UVB) appear necessary to produce radical pairs and conditions favorable for allowing the expression of MIE. In support this conclusion, there are several studies that demonstrate direct photolysis of $\mathrm{Hg}$ complexes that have radical pair intermediates by UVA and UVB (Friswell and Gowenlock, 1965; Zepp et al. 1973; Inoko, 1981; Tossell, 1998; Gardfeldt and Jonsson, 2003; Lin and Ariya, 2008; Tai et al., 2014).

The disappearence of MIF does not, however, neccesarily indicate the disappearence of direct photolysis of $\mathrm{Hg}$ species. Not all direct photolysis reactions with radical pair intermediates will have conditions favorable for expressing the MIE (Turro, 1983; Grissom, 1995; Buchachenko, 2001). For direct photo-reduction to result in MIF, the rate-limiting step needs to involve an excited radical pair intermediate where hyper-fine interactions (HFI) can influence the spin of the unpaired electrons and the fate of the radical pair intermediate. For example, the lifetime and coupling of the radical pair as well as the solvent cage are all important variables that may affect expression of MIE induced MIF (Turro, 1983; Buchachenko, 2001; Turro et al., 2009). If the lifetime of the radical pair is too short, then HFI induced spin conversion cannot compete with dissociation into free radicals (Turro, 1983; Turro et al., 2008). The distance (or coupling) of the radical pair is also important (Turro, 1983; Turro et al., 2008). In order for HFI to effectively induce spin conversion, the radical fragments must separate to a physical distance where the energy gap between the singlet and triplet states is of the same order or smaller than the hyperfine interaction (Turro et al., 2008). At such a distance, the original chemical bond will have completely dissociated and one or more solvent molecules may separate the radicals. The probability of the newly-singlet radical fragments reencountering each other before separating completely is high because they will "bounce" against the surrounding solvent molecules and each other several times before finding avenues through the solvent to become fully separated (Turro et al., 2008).

The data in this paper shows no strong correlation between MIF and total photoreduction. Therefore, we suggest that $\mathrm{Hg}$ photo-reduction reactions that lead to MIE in our experiments are likely only a small portion of multiple reactions that resulted in photoreduction. Although not all direct photolysis reactions may lead to MIE, MIE may still be a good indication of the extent of direct photolysis since excited radical pairs require higher 
energy radiation to be generated. If such high energy is available for direct photolysis leading to MIE, then it is also available for direct photolysis that does not lead to MIE. Thus the lack of correlation between MIF and total photo-reduction may be an indication that indirect photoreduction is dominating in many of our experiments. This is especially true for the $\mathrm{MMHg}$ photo-degradation experiments where no significant suppression of photo-degradation is observed when blocking out UV radiation, with the exception of a slight suppression for the UVA and UVB filtered experiment in September. Since the $\mathrm{Hg}^{2+}$ experiments show suppression of total photo-reduction when all UV was blocked, direct photolysis was likely more important in those experiments.

Although the exact pathway of indirect photolysis is unclear from the current experiments, there are a number of studies that have investigated indirect pathways for photoreduction of $\mathrm{Hg}$ by reactive photo-generated intermediates. Indirect photolysis leading to stepwise reduction of aqueous $\mathrm{Hg}^{2+}$ to $\mathrm{Hg}^{0}$ with formic acid and visible light (Zheng et al., 2005) showed that formic acid decomposes to produce hydrogen and carbon monoxide under environmentally available wavelengths (Allmand and Reeve, 1926), and thus photo-generated reactive intermediates such as $\bullet \mathrm{H}$ and $\mathrm{CO} \cdot$ can be responsible for the $\mathrm{Hg}^{0}$ production. In another study, other low molecular weight organic molecules (formaldehyde, methanol, acetic acid, glycerol, oxalic and malonic acid) also can reduce $\mathrm{Hg}^{2+}$ to $\mathrm{Hg}^{0}$ in aqueous solution when exposed to light (Han et al., 2007). Hydroxyl radicals have also been shown to degrade MMHg (Chen et al., 2003), however, Zhang and Hsu-Kim (2010) point out that under natural conditions substrate abundance and $\mathrm{pH}$ do not always favor a concentration of $\cdot \mathrm{OH}$ radicals high enough to account for the MMHg degradation rates reported for natural systems, and present a strong case for the role of singlet oxygen in the decomposition of MMHg.

\section{4. $\Delta^{199} \mathrm{Hg} / \Delta^{201} \mathrm{Hg}$}

In examining MIF during photo-reduction of $\mathrm{Hg}^{2+}$, Bergquist and Blum (2007) observed that the ratio $\square$ of $\Delta{ }^{199} \mathrm{Hg} / \Delta^{201} \mathrm{Hg}$ was very consistent $(1.00 \pm 0.02,2 \mathrm{SE})$ and distinct from the ratio $\square \Delta^{199} \mathrm{Hg} / \Delta^{201} \mathrm{Hg}$ resulting from photo-degradation of MMHg (1.36 $\left.\pm 0.02,2 \mathrm{SE}\right)$. The $\Delta^{199} \mathrm{Hg} / \Delta^{201} \mathrm{Hg}$ ratio produced by the nuclear volume effect (NVE) contrasts with these values and is now theoretically (Schauble, 2007; Wiederhold et al., 2010) and experimentally 
constrained at $\sim 1.59 \pm 0.05$ (2SE) (Wiederhold et al., 2010; Zheng and Hintelmann 2010b,

498 Ghosh et al., 2013). The $\Delta^{199} \mathrm{Hg} / \Delta^{201} \mathrm{Hg}$ ratios produced in this study agree well with Bergquist and Blum (2007), which is not surprising since both studies used the same source of DOM,

500

501

502

503

504

505

506

507

508

509

510

511

512

513

514

515

516

517

518

519

520

521

522

523

524

525

526

527 natural sunlight and similar $\mathrm{Hg} / \mathrm{DOM}$ ratios. The difference in the $\Delta^{199} \mathrm{Hg} / \Delta^{201} \mathrm{Hg}$ relationship between $\mathrm{Hg}^{2+}$ and $\mathrm{MMHg}$ photo-reduction indicates that the different reactions that lead to MIE-induced MIF for these two $\mathrm{Hg}$ species have different relative rates of spin conversion for ${ }^{199} \mathrm{Hg}$ and ${ }^{201} \mathrm{Hg}$.

The $\Delta^{199} \mathrm{Hg} / \Delta^{201} \mathrm{Hg}$ ratio for all $\mathrm{Hg}^{2+}$ photo-reduction experiments in this work falls within error of 1.0. If the ratio is indeed indicative of the pathway, then the pathway resulting in MIF in our experiments may be constant even when higher energy radiation is filtered out and the amount of photo-reduction is reduced. Although there could also be multiple reactions that have a MIE slope of $\sim 1$. The ratio in this study agrees well with natural samples containing inorganic $\mathrm{Hg}^{2+}$, which have a $\Delta^{199} \mathrm{Hg} / \Delta^{201} \mathrm{Hg}$ slope of $0.98 \pm 0.02$ (2SE) (see review: Sonke, 2011). Although the $\square \Delta^{199} \mathrm{Hg} / \Delta^{201} \mathrm{Hg}$ relationship observed in this study agrees well with Bergquist and Blum, 2007, and the inorganic $\mathrm{Hg}^{2+}$ dominated natural samples, it is different from ratios observed in experiments by Zheng and Hintelman (2009, 2010a). Under varying DOM amounts and types, and using an artificial light source, these authors observed ratios for $\mathrm{Hg}^{2+}$ photo-reduction varying from 1.0 to 1.3. The difference between Zheng and Hintelmann's results and the ratios observed by Bergquist and Blum (2007), this study, and natural samples still needs to be resolved, but may be related to the type and amount of organic matter used or the use of different light sources (i.e., natural sun versus artificial light).

The average ratio $\Delta^{199} \mathrm{Hg} / \Delta^{201} \mathrm{Hg}$ for all $\mathrm{MMHg}$ experiments in this work was $1.35 \pm 0.16$ (2SE), which is similar to the value obtained by Bergquist and Blum (2007) (1.36 $\pm 0.02,2 \mathrm{SE})$, also under natural sunlight. Chandan et al. (2014) found variable $\Delta^{199} \mathrm{Hg} / \Delta^{201} \mathrm{Hg}$ for $\mathrm{MMHg}$ photo-degradation for different DOM types and amounts using an artificial light source. Experiments by Chandan et al. (2014) with low $\mathrm{MMHg} / \mathrm{DOM}$ ratios had a consistent $\Delta^{199} \mathrm{Hg} / \Delta^{201} \mathrm{Hg}$ ratio of $1.38 \pm 0.02(2 \mathrm{SE})$; whereas higher $\mathrm{MMHg} / \mathrm{DOM}$ ratio experiments had more lower slopes of $1.17 \pm 0.04(2 \mathrm{SE}, \mathrm{n}=7)$ to $1.30 \pm 0.02(2 \mathrm{SE})$. Malinkovsky et al., 2010, reported a slightly lower ratio $(1.28 \pm 0.03,1 \mathrm{SD})$ for experimental photo-degradation of $\mathrm{MMHg}$ under UVC radiation. The causes of variable $\Delta^{199} \mathrm{Hg} / \Delta^{201} \mathrm{Hg}$ ratios with respect to the MIE are not completely understood and a more quantitative understanding of the MIE is needed. 
The results from our experiments should not be simply extrapolated to natural systems. Although the total extent of photo-reduction was found in this study to be decoupled from both MIF magnitude and energy of incident radiation, the experiments are not representative of the photo-reduction in natural freshwaters and did not use realistic $\mathrm{Hg}$ :DOM ratios. In this study the experiments were stirred exposing the entire reservoir to sunlight. In natural systems, the amount of solar radiation is attenuated with depth and the amount of the water column that can undergo photochemical reactions is limited (Morris et al., 1995; Williamson et al., 1996). Thus, the amount of both direct and indirect photo-reduction will be related to the penetration of solar radiation. As long as MIF is related to the depth of UV penetration, then it is likely that MIF will be related to the amount of direct photochemical reduction. However, based on our experiments, the relationships between MIF and total photo-reduction might depend on the relative depths of UV versus PAR penetration for lakes, which is dependent on type and amount of DOC (Morris et al., 1995; Williamson et al., 1996). Incident radiation as measured by photon flux is attenuated in fresh water predominantly by DOM. The depth of $90 \%$ attenuation can be as large as $5 \mathrm{~m}$ for UVB in low-DOC (clear) aquatic systems and as small as a few cm for high-DOC (humic) aquatic systems (Scully and Lean, 1994; Morris et al., 1995; Crump et al., 1999; Belmont et al., 2007). Depths of $90 \%$ attenuation for PAR are typically 4 or 5 times larger, with UVA at intermediate values (Scully and Lean, 1994; Morris et al., 1995, Crump et al., 1999, Belmont et al., 2007). Our data, therefore, suggest that in a clear, low DOC lake total photo-reduction will be far more important and dominated by a larger MIE MIF signature than in a darker high DOC lake. Thus, there is the potential for useful relationships to

\section{Conclusions}

555

Photo-reduction experiments of $\mathrm{Hg}^{2+}$ and $\mathrm{MMHg}$ in the presence of DOM were 557 conducted with exposure to unfiltered full natural solar spectrum, with the ultraviolet B (UVB; 558 290-320 nm) portion removed and with both the UVB and the ultraviolet A (UVA; 320-400 
$\mathrm{nm})$ removed. There was a clear relationship between the expression and magnitude of MIF and the energy of incident radiation for both $\mathrm{Hg}^{2+}$ and $\mathrm{MMHg}$ in the experiments in this study. This supports the MIE as the mechanism behind large MIF in photo-reduction of mercury species. For $\mathrm{Hg}^{2+}$, UVB radiation was a major contributor to MIF and UVA radiation seems to contribute significantly as well. For MMHg, UVB radiation was the major contributor to MIF with minor contributions from UVA. The lack of correlation observed between MIF and total photo-reduction may be an indication that indirect photo-reduction was dominating in many of the experiments. This was especially true for the MMHg photo-degradation experiments where no significant suppression of photo-degradation was observed when blocking out UV while MIF is significantly suppressed. $\mathrm{Hg}^{2+}$ experiments showed more suppression of total photoreduction when UV is blocked and therefore direct photolysis was likely more important in these experiments. Ratios $\square$ of $\Delta^{199} \mathrm{Hg} / \Delta^{201} \mathrm{Hg}$ remained consistent for each of the species undergoing photo-reduction $\left(0.98 \pm 0.04,2 \mathrm{SE}\right.$ for $\mathrm{Hg}^{2+}$ and $1.33 \pm 0.14,2 \mathrm{SE}$ for $\left.\mathrm{MMHg}\right)$ regardless of the energy of incident radiation. This is consistent with previous reports of MIF caused by the MIE and distinct from $\Delta^{199} \mathrm{Hg} / \Delta^{201} \mathrm{Hg}$ ratios attributed to the NV effect $(\sim 1.6)$. While total photo-reduction in the experiments in this study was decoupled from both MIF magnitude and energy of incident radiation, the clear relationship between MIF and energy of incident radiation and the fairly predictable relationships of UV radiation to PAR in natural systems still suggests that MIF signatures have a strong potential to constrain aspects of $\mathrm{Hg}$ photo-reduction. However, in order to use MIF preserved in natural samples more quantitatively, more work is needed to elucidate the relationship between MIF and photoreduction in natural systems.

\section{Acknowledgements}

We thank Marcus Johnson for mass spectrometry analysis at the University of Michigan. Funding was provided by grants from NSERC-Discovery to BAB, NSF (EAR-0952108) to JDB and BAB and US DOE Office of Science (BER; DE-SC0007042) to JDB.

\section{Figure Captions:}


Figure 1. Mercury concentration in the substrate reservoir over time for replicate photoreduction experiments on two $\mathrm{Hg}$ species $\left(\mathrm{Hg}^{2+}\right.$ and monomethylmercury, $\left.\mathrm{MMHg}\right)$ in the presence of dissolved organic matter and under varying exposure to solar radiation. Maxima in solar irradiation were recorded at approximately $1 \mathrm{pm}$, Eastern Standard Time, coinciding with solar noon in Toronto, Ontario. Effective blocking of the UVB spectrum resulted in partial blocking of the UVA spectrum (by 30 to 52\%). Complete radiation measurements are shown in Table S1 of the Supplemental Information. Dark controls were carried out with a foil-wrapped reactor.

Figure 2. Mass-dependent fractionation $\left(\delta^{202} \mathrm{Hg}\right)$ of the substrate reservoir as a function of $\mathrm{Hg}$ remaining for replicate photo-reduction experiments on $\mathrm{Hg}^{2+}$ and $\mathrm{MMHg}$ with dissolved organic matter under varying exposure to solar radiation. Rayleigh distillation models using estimated fractionation factors $\left(\alpha_{\Delta 202}\right)$ are shown where there was significant loss in concentration. Solid black lines: full sun; broken grey lines: UVB spectrum blocked. Complete isotope data are given in Tables S2 and S3 of the Supplemental Information.

Figure 3. MIF, $\Delta^{199} \mathrm{Hg}$, in odd isotopes as a function of substrate $\mathrm{Hg}^{+2}$ remaining during photoreduction in the presence of DOM under varying exposure to solar radiation. Rayleigh distillation models based on estimated MIF factors $\left(\alpha_{\Delta 199}\right)$ are shown for experiments with signficant MIF. Solid black lines: full sun (July $\alpha_{\Delta 199}=0.9986 \pm 0.0001 ;$ Sept $\alpha_{\Delta 199}$ $=0.9993 \pm 0.0002)$. Broken grey lines: UVB spectrum blocked (July $\alpha_{\Delta 199}=0.9993 \pm$ 0.0001 ; Sept $\alpha_{\Delta 199}=0.9995 \pm 0.0001$ ). Complete isotope data are given in Tables S2 and S3 of the Supplemental Information.

Figure 4. MIF, $\Delta^{199} \mathrm{Hg}$ in odd isotopes as a function of substrate MMHg remaining during photo-reduction in the presence of DOM under varying exposure to solar radiation. Rayleigh distillation models (solid black lines) based on an estimated MIF factors $\left(\alpha_{\Delta 199}\right)$ are shown for experiments with signficant MIF, which was only for the full sun experiments (July $\alpha_{\Delta 199}=0.9977 \pm 0.0011 ;$ September $\alpha_{\Delta 199}=0.9964 \pm 0.0014$ ) Complete isotope data are given in Tables S2 and S3 of the Supplemental Information.

Figure 5. $\Delta^{201} \mathrm{Hg}$ versus $\Delta^{199} \mathrm{Hg}$ for photochemical reduction of $\mathrm{Hg}^{2+}$ and MMHg in the presence of dissolved organic matter under varying exposure to solar radiation. Only samples with significant MIF were plotted, so R0 (pre-exposure) and R1 (taken immediately after first exposure to solar radiation) do not appear for any experiment. For $\mathrm{Hg}^{+2}$, the average $\Delta^{201} \mathrm{Hg} / \Delta{ }^{199} \mathrm{Hg}$ is $0.98 \pm 0.04,2 \mathrm{SE}, \mathrm{n}=16$ (black line). For MMHg, the average $\Delta^{201} \mathrm{Hg} / \Delta{ }^{199} \mathrm{Hg}$ is $1.33 \pm 0.14,2 \mathrm{SE}, \mathrm{n}=4$ (broken line). 


\section{References}

Allmand, A. J. and Reeve, L. J. 1926. The photochemical decomposition of aqueous formic acid solutions. Journal of the Chemical Society 129, 2852-2863.

Amyot, M., Mierle, G., Lean, D. R. S., McQueen, D. J., 1994. Sunlight-induced formation of dissolved gaseous mercury in lake waters. Environmental Science and Technology 28,

Amyot, M., Mierle, G., Lean, D., McQueen, D. J., 1997. Effect of solar radiation on the formation of dissolved gaseous mercury in temperate lakes. Geochimica et Cosmochimica Acta 61, 975-987.

Belmont, P., Hargreaves, B. R., Morris, D. P., Willamson, C. E., 2007. Estimating attenuation of ultraviolet radiation in streams: Field and laboratory methods. Photochemistry and Photobiology 83, 1339-1347.

Bergquist, B. A. and Blum, J. D., 2007. Mass-dependent and mass-independent fractionation of $\mathrm{Hg}$ isotopes by photoreduction in aquatic systems. Science 318, 417-420.

Bergquist, B. A. and Blum, J. D., 2009. The odds and evens of mercury isotopes: Applications of mass-dependent and mass-independent isotope fractionation. Elements 5, 353-357.

Bigeleisen J., 1996. Nuclear size and shape effects in chemical reactions. Isotope chemistry of the heavy elements. Journal of the American Chemical Society 118, 3676-3680.

Black, F. J, Poulin, B. A., Flegal, A. R., 2012. Factors controlling the abiotic photo-degradation of monomethylmercury in surface waters. Geochimica et Cosmochimica Acta 84, 492- 507.

Blum, J. D. and Bergquist, B. A., 2007. Reporting of variations in the natural isotopic composition of mercury. Analytical and Bioanalytical Chemistry 388, 353-359.

Blum, J.D., 2012. Applications of stable mercury isotopes to biogeochemistry. In Handbook of Environmental Isotope Geochemistry; Baskaran, M., Eds.; Springer-Verlag Berlin Heidelberg, 229-246.

Blum, J. D.; Popp, B. N.; Drazen, J. C.; Choy, A., 2013. Johnson, M. W. Methylmercury production below the mixed layer in the North Pacific Ocean. Nature Geoscience 6, 879-884.

Buchachenko, A. L., 2001. Magnetic isotope effect: Nuclear spin control of chemical reactions. Journal of Physical Chemistry A 105, 9995-10011.

Buchachenko, A. L., Ivanov, V. L., Roznyatovskii, V. A., Artamkina, G. A., Vorob’ev, A., Kh., Ustynyuk, Yu. A., 2007. Magnetic isotope effect for mercuy nuclei in photolysis of bis(ptrifluoromethylbenzyl)mercury. Doklady Physical Chemistry 413, 39-41.

Chandan, P., Ghosh, S., Bergquist, B.A., 2014. Mercury isotope fractionation during aqueous photoreduction of monomethylmercury in the presence of dissolved organic matter. Environmental Science and Technology 49, 259-267.

Chen, J., Pehkonen, S. O., and Lin, C. J., 2003. Degradation of monomethylmercury chloride by hydroxyl radicals in simulated natural waters. Water Research 37, 2496-2504.

Crump, D., Lean, D., Berrill, M., Coulson, D., Toy, L., 1999. Spectral irradiance in pond water: Influence of water chemistry. Photochemistry and Photobiology 70, 893-901. 
Fernańdez-Goḿez, C., Drott, A., Björn, E., Díez, S., Bayona, J. M., Tesfalidet, Lindfors, A., Skyllberg, U., 2013. Towards universal wavelength-specific photodegradation rate constants for methyl mercury in humic waters, exemplified by a boreal lake-wetland gradient. Environmental Science and Technology 47, 6279-6287.

Fitzgerald, W.F. and Lamborg, C.H., 2014. Geochemistry of mercury in the environment, In Treatise on Geochemistry (Second Edition), edited by Heinrich D. Holland and Karl K. Turekian, Elsevier, Oxford, Pages 91-129.

Friswell and Gowenlock, 1965. Advances in Free Radical Chemistry 1, 39.

Gantner, N., Hintelmann, H., Zheng, W., and Muir, D. C., 2009. Variations in stable isotope fractionation of $\mathrm{Hg}$ in food webs of Arctic lakes. Environmental Science \& Technology 43, 9148-9154.

Garcia, E., Poulain, A. J., Amyot, M., and Ariya, P. A., 2005. Diel variations in photoinduced oxidation of $\mathrm{Hg}-0$ in freshwater. Chemosphere 59, 977-981.

Gardfeldt, K. and Jonsson, M., 2003. Is bimolecular reduction of divalent $\mathrm{Hg}$ complexes possible in aqueous systems of environmental importance. Journal of Physical Chemistry A 107, 44784482 .

Gehrke, G. E., Blum, J. D., Slotton, D. G., Greenfield, B. K., 2011. Mercury isotopes link mercury in San Francisco bay forage fish to surface sediments. Environmental Science \& Technology, 45, 1264-1270.

Ghosh, S., Schauble, E.A., Lacrampe Couloume, G., Blum, J.D., Bergquist, B.A., 2013. Estimation of nuclear volume dependent fractionation of mercury isotopes in equilibrium liquid-vapor evaporation experiments. Chemical Geology, 366, 5-12.

Grissom, C. B., 1995. Magnetic field effects in Biology: A survey of possible mechanisms with emphasis on radical pair recomibination. Chemical Reviews 95. 3-24.

Hammerschmidt, C. R. and Fitzgerald, W. F., 2006. Photodecomposition of methylmercury in an arctic Alaskan lake. Environmental Science \& Technology 40, 1212-1216.

Hammerschmidt, C. R. and Fitzgerald, W. F., 2010. Iron-mediated photochemical decomposition of methylmercury in an arctic Alaskan lake. Environmental Science \& Technology 44, 61386143.

Han, C. F., Zheng, C. B., Wang, J., Cheng, G. L., Lv, Y., and Hou, X. D., 2007. Photo-induced cold vapor generation with low molecular weight alcohol, aldehyde, or carboxylic acid for atomic fluorescence spectrometric determination of mercury. Analytical and Bioanalytical Chemistry 388, 825-830.

Horvath, O., Valicsek, Z. and Vogler, A., 2004. Unique photoreactivity of mercury (II) 5,10,15,20-tetrakis (4-sulfonatophenyl)porphyrin. Inorganic Chemistry Communications 7, 854-857.

Inoko, M., 1981. Studies on the photochemical decomposition of organomercurialsmethylmercury(II) chloride. Environmental Pollution Series B-Chemical and Physical 2, 310 . 
Kern, R. J., 1952. The photolysis of some mercury dimercaptides. Journal of the American Chemical Society 75, 1865-1866.

Kim, M. K., Zoh, K. D., 2013. Effects of natural water constituents on the photo-decomposition of methylmercury and the role of hydroxyl radical. The Science of the Total Environment 449, 95-101.

Krabbenhoft, D. P., Hurley, J. P., Olson, M. L., Cleckner, L. B., 1998. Diel variability of mercury phase and species distributions in the Florida Everglades. Biogeochemistry 40, 311325.

Kunkely, H., Horvath, O., and Vogler, A., 1997. Photophysics and photochemistry of mercury complexes. Coordination Chemistry Reviews 159, 85-93.

Kwon, S. Y., Blum, J. D., Chen, C. Y., Meattey, D. E., Mason, R. P., 2014. Mercury isotope study of sources and exposure pathways of methylmercury in estuarine food webs in the Northeastern U.S. Environmental Science \& Technology 48, 10089-10097.

Laffont, L., Sonke, J. E., Maurice, L., Hintelmann, H., Pouilly, M., Bacarreza, Y. S., Perez, T., and Behra, P., 2009. Anomalous Mercury Isotopic Compositions of Fish and Human Hair in the Bolivian Amazon. Environmental Science \& Technology 43, 8985-8990.

Lauretta, D. S., Klaue, B., Blum, J. D., and Buseck, P. R., 2001. Mercury abundances and isotopic compositions in the Murchison (CM) and Allende (CV) carbonaceous chondrites. Geochimica Et Cosmochimica Acta 65, 2807-2818.

Lehnherr, I. and Louis, V. L. S., 2009. Importance of Ultraviolet Radiation in the Photodemethylation of Methylmercury in Freshwater Ecosystems. Environmental Science \& Technology 43, 5692-5698.

Li, Y., Mao, Y., Liu, G., Tachiev, G., Roelant, D., Feng, X., et al, 2010. Degradation of methylmercury and its effects on mercury distribution and cycling in the Florida Everglades. Environmental Science \& Technology 44, 6661-6666.

Lin, S. and Ariya, P., 2008. Reduction of oxidized mercury species by dicarboxylic acids (C-2C-4): Kinetic and product studies. Environmental Science \& Technology 42, 5150-5155.

Malinovsky, D., Latruwe, K., Moens, L., and Vanhaecke, F., 2010. Experimental study of massindependence of $\mathrm{Hg}$ isotope fractionation during photodecomposition of dissolved methylmercury. Journal of Analytical Atomic Spectrometry 25, 950-956.

Mariotti, A., Germon, J. C., Hubert, P., Kaiser, P., Letolle, R., Tardieux, A., and Tardieux, P., 1981. Experimental-determination of nitrogen kinetic isotope fractionation - some principles illustration for the denitrification and nitrification processes. Plant and Soil 62, 413-430.

Morris, D. P., Zagarese, H., Williamson, C. E., Balseiro, E. G., Hargreaves, B. R., Modenutti, B., Moeller, R., Queimalinos, C., 1995. The attentuation of solar UV radiation in lakes and the role of dissolved organic carbon. Limnology and Oceanography 40, 1381-1391.

O’Driscoll, N. J., Lean, D. R. S., Loseto, L. L., Carignan, R., Siciliano, S. D., 2004. Effect of dissolved organic carbon on the photoproduction of dissolved gaseous mercury in lakes: Potential impacts of forestry. Environmental Science and Technology, 38, 2664-2672. 
O’Driscoll, N. J., Siciliano, S. D., Lean, D. R. S., Amyot, M., 2006. Gross photoreduction kinetics of mercury in temperate freshwater lakes and rivers: Application to a general model of DGM dynamics. Environmental Science and Technology, 40, 837-843.

Perrot, V., Epov, V., Pastukhov, M., Grebenshchikova, V., Zouiten, C., Sonke, J.E., Husted, S., Donard, O.F.X. and Amouroux, D., 2010. Tracing sources and bioaccumulation of mercury in fish of Lake Baikal - Angara River using $\mathrm{Hg}$ isotopic composition. Environmental Science and Technology, 44, 8030-8037.

Poulain, A. J., Amyot, M., Findlay, D., Telor, S., Barkay, T., Hintelmann, H., 2004. Biological and photochemical production of dissolved gaseous mercury in a boreal lake. Limnology and Oceanography 49, 2265-2275.

Qian, Y., Yin, X., Lin, H., Rao, B., Brooks, S. C., Liang, L., Gu, B., 2014. Why dissolved organic matter enhances photodegradation of methylmercury. Environmental Science and Technology, dx.doi.org/10.1021/ez500254z.

Ravichandran, M., 2004. Interactions between mercury and dissolved organic matter - a review. Chemosphere 55, 319-331.

Scully, N. M., Lean, D. R. S., 1994. The attenuation of ultraviolet radiation in temperate lakes. Ergeb Limnology 43, 135-144.

Sellers, P., Kelly, C. A., Rudd, J. W. M., and MacHutchon, A. R., 1996. Photodegradation of methylmercury in lakes. Nature 380, 694-697.

Senn, D. B., Chesney, E. J., Blum, J. D., Bank, M.S., Maage, A., Shine, J. P., 2010. Stable isotope $(\mathrm{N}, \mathrm{C}, \mathrm{Hg})$ study of methylmercury sources and trophic transfer in the northern Gulf of Mexico. Environmental Science and Technology 44, 1630-1637.

Sherman, L. S., Blum, J. D., Johnson, K. P., Keeler, G. J., Barres, J. A., and Douglas, T. A., 2010. Mass-independent fractionation of mercury isotopes in Arctic snow driven by sunlight. Nature Geoscience 3, 173-177.

Sherman, L.S., Blum, J.D., 2013. Mercury stable isotopes in sediments and largemouth bass (Micropterus salmoides) from Florida lakes. Science of the Total Environment, 448, 163-175.

Tai, C., Li, Y., Yin, Y., Scinto, L. J., Jiang, G., Cai, Y., 2014. Methylmercury photodegradation in surface water of the Florida Everglades: importance of dissolved organic mattermethylmercury complexation. Environmental Science and Technology 48, 7333-7340.

Tossell, J. A., 1998. Theoretical study of the photodecomposition of methyl $\mathrm{Hg}$ complexes. Journal of Physical Chemistry A 102, 3587-3591.

Tsui, M. T., Blum, J. D., Finlay, J. C., Balogh, S. J., Nollet, Y. H., Palen, W. J., Power, M. E., 2014. Variation in terrestrial and aquatic sources of methylmercury in stream predators as revealed by stable mercury ssotopes. Environmental Science and Technology 48, 10128-10135.

Turro, N. J., 1983. Influence of nuclear spin on chemical reactions: Magnetic isotope and magnetic field effects (a review). Proceedings of the National Acadamy of Sciences USA 80, 609-621. 
Turro, N., Scaiano, J. C., and Ramamurthy, V., 2008. Principles of Molecular Photochemistry: An Introduction. University Science Books.

Wiederhold, J. G., Cramer, C. J., Daniel, K., Infante, I., Bourdon, B., and Kretzschmar, R., 2010. Equilibrium mercury isotope fractionation between dissolved $\mathrm{Hg}$ (II) species and thiol-bound Hg. Environmental Science \& Technology 44, 4191-4197.

Williamson, C. E., Stemberger, R. S., Morris, D. P., Frost, T. M., Paulsen, S. G., 1996, Ultraviolet radiation in North American lakes: Attenuation estimates from DOC measurements and implications for plankton communities. Limnology and Oceanography 41, $1024-1034$.

Young, E. D., Galy, A., and Nagahara, H., 2002. Kinetic and equilibrium mass-dependent isotope fractionation laws in nature and their geochemical and cosmochemical significance. Geochimica Et Cosmochimica Acta 66, 1095-1104.

Zepp, R. G., Wolfe, L., and Gordon, J. A., 1973. Photodecomposition of phenylmercury compounds in sunlight. Chemosphere, 93-99.

Zhang, T. and Hsu-Kim, H., 2010. Photolytic degradation of methylmercury enhanced by binding to natural organic ligands. Nature Geoscience 3, 473-476.

Zheng, C. B., Li, Y., He, Y. H., Ma, Q., and Hou, X. D., 2005. Photo-induced chemical vapor generation with formic acid for ultrasensitive atomic fluorescence spectrometric determination of mercury: potential application to mercury speciation in water. Journal of Analytical Atomic Spectrometry 20, 746-750.

Zheng, W. and Hintelmann, H., 2009. Mercury isotope fractionation during photoreduction in natural water is controlled by its $\mathrm{Hg} / \mathrm{DOC}$ ratio. Geochimica Et Cosmochimica Acta 73, 67046715 .

Zheng, W. and Hintelmann, H., 2010a. Isotope fractionation of mercury during its photochemical reduction by low-molecular-weight organic compounds. Journal of Physical Chemistry A 114, 4246-4253.

Zheng, W. and Hintelmann, H., 2010b. Nuclear field shift effect in isotope fractionation of mercury during abiotic reduction in the absence of light. Journal of Physical Chemistry A 114, 4238-4245.

Xiao, Z. F., Stromberg, D., Lindqvist, O., 1995. Influence of humic substances on the photolysis of divalent mercury in aqueous solution. Water, Air, and Soil Pollution 80, 789-798. 


\section{Figure 1}

Click here to download high resolution image

\section{Figure 1}
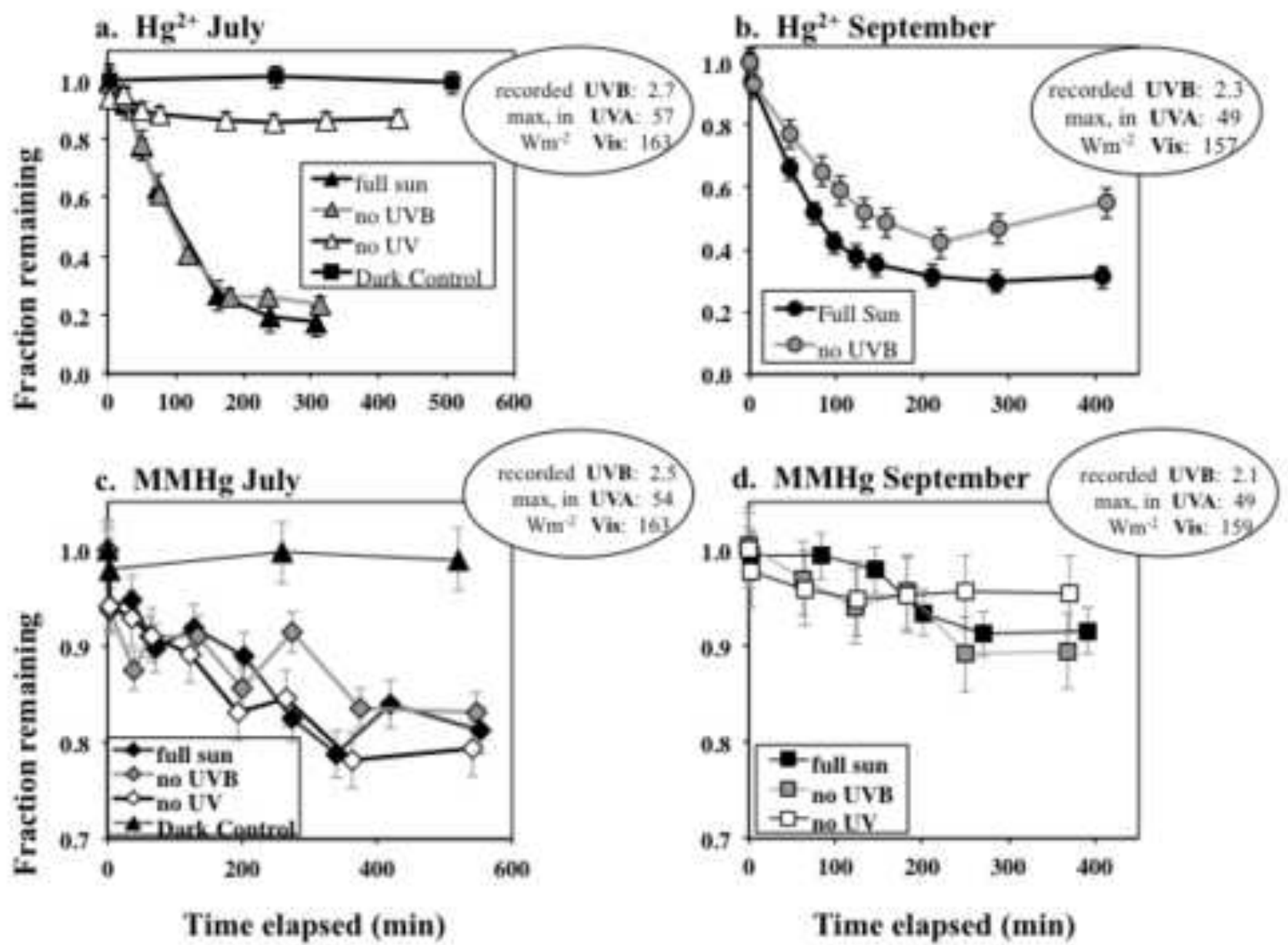
Figure 2
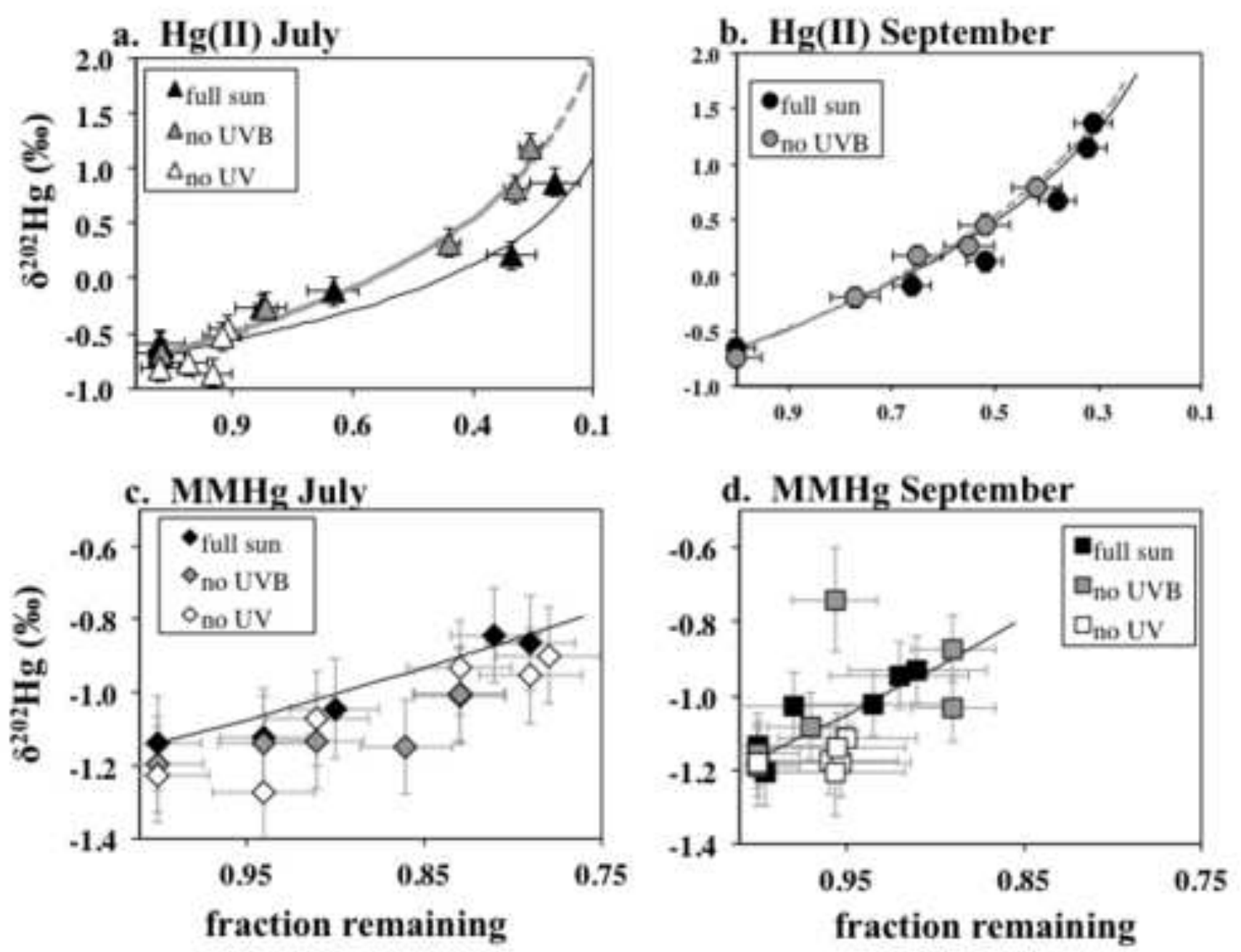
Figure 3
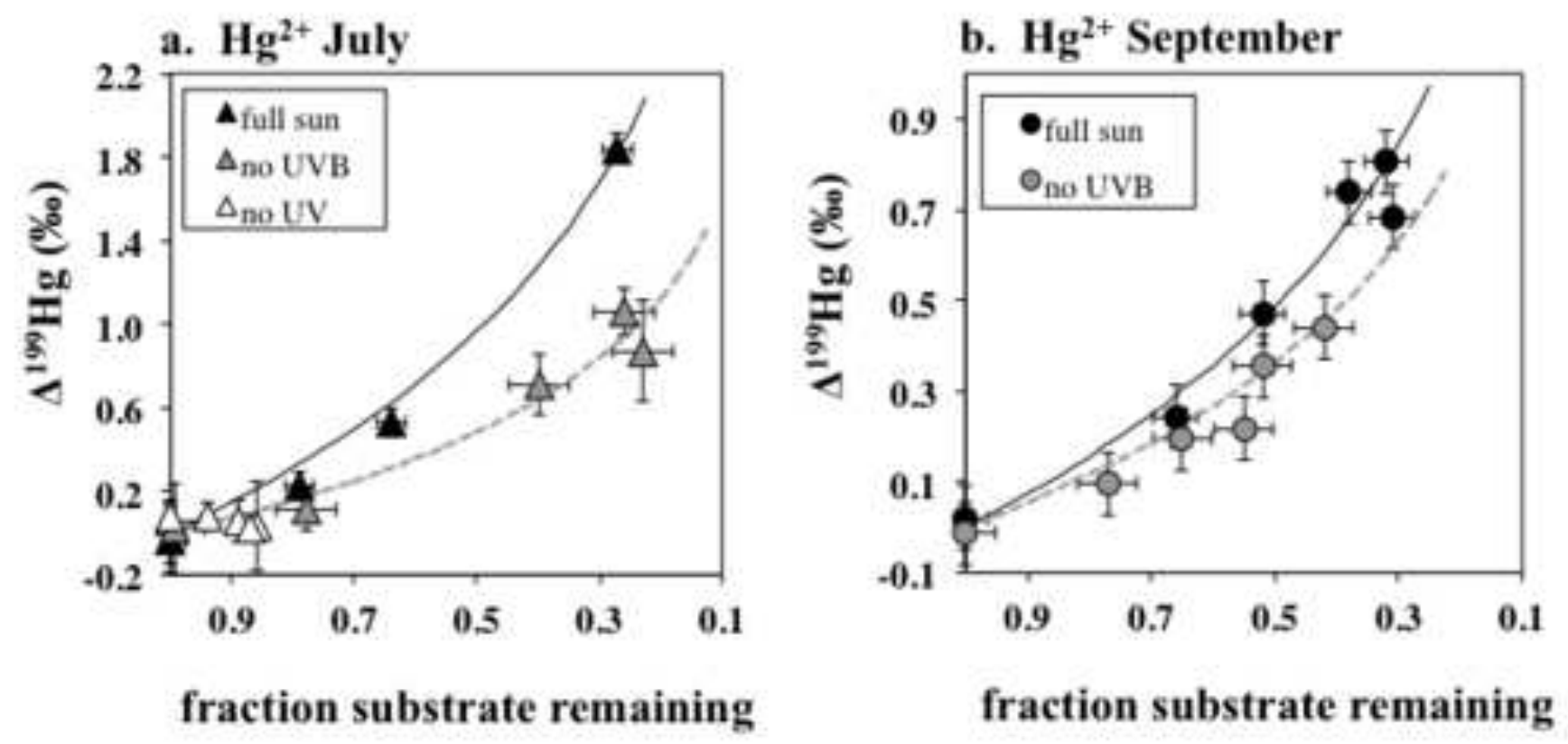
Figure 4

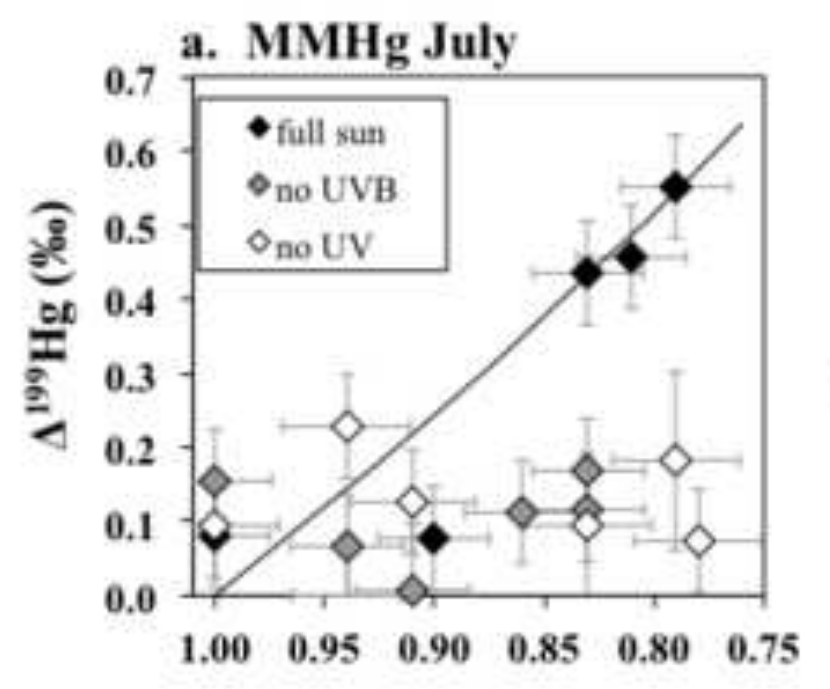

fraction substrate remaining

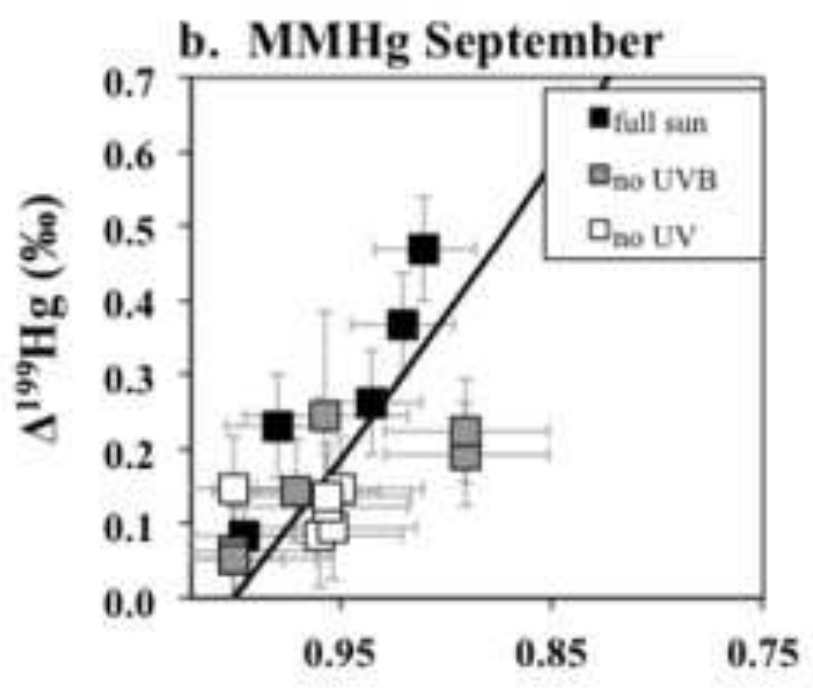

fraction substrate remaining 
Figure 5
Click here to download high resolution image

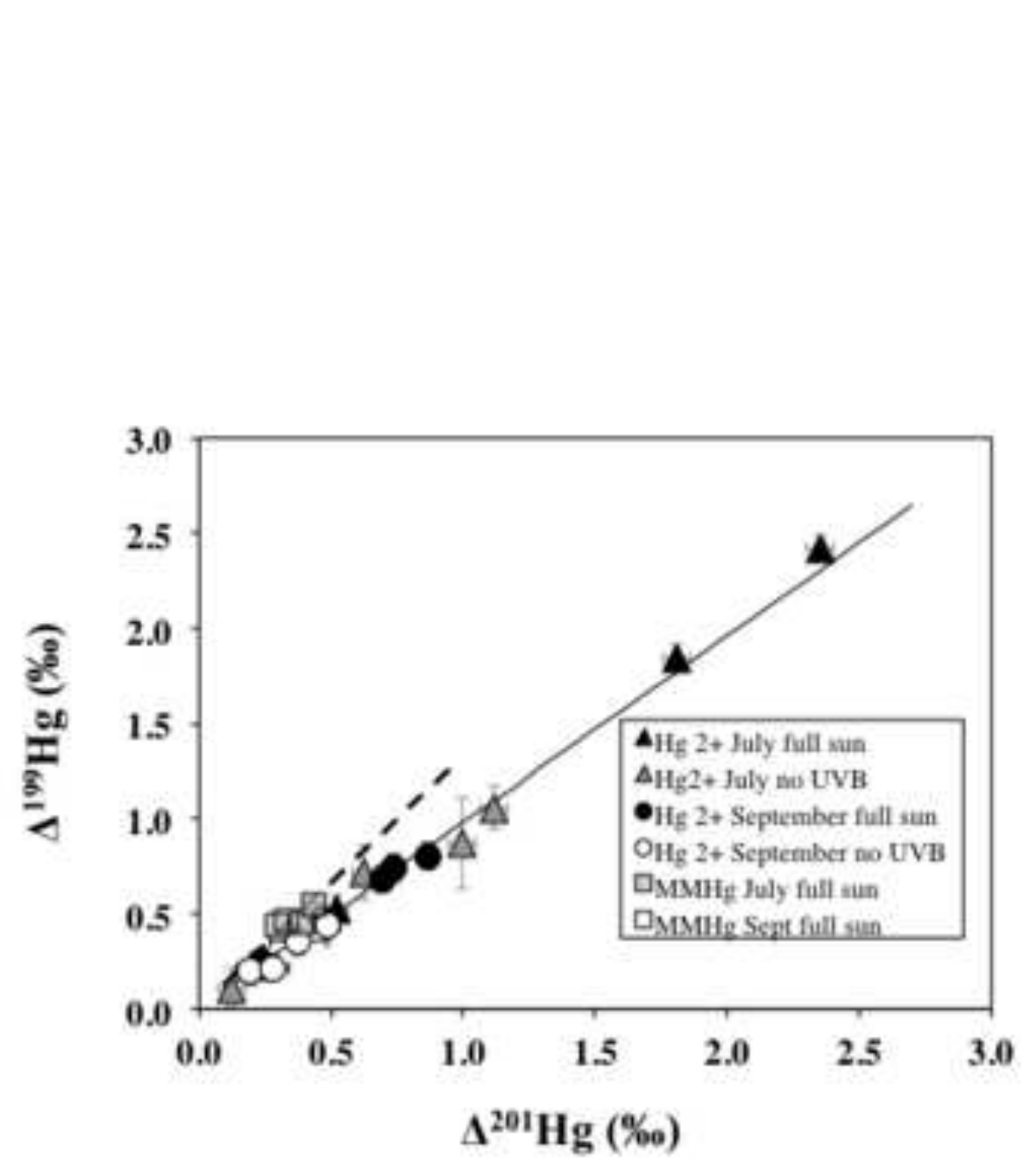

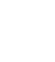

\section{Figure 5 \\ Figure 5}

等

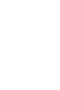


Table S1. Solar radiation measurements

\begin{tabular}{|c|c|c|c|c|c|c|c|c|}
\hline Mercury Species & \multicolumn{4}{|c|}{$\mathrm{Hg}^{2+}$} & \multicolumn{4}{|c|}{$\mathrm{Hg}^{2+}$} \\
\hline Date performed & \multicolumn{4}{|c|}{ July 29,2009} & \multicolumn{4}{|c|}{ September 03, 2009} \\
\hline $\begin{array}{l}\text { Photoexperiment } \\
\text { exposure }\end{array}$ & full sun & no UVB & no UV & $\begin{array}{c}\text { Time of } \\
\text { Day }\end{array}$ & full sun & no UVB & & Time of Day \\
\hline Spectrum & \multicolumn{3}{|c|}{ Radiation Measured $\left(\mathrm{W} / \mathrm{m}^{2}\right)$} & & \multicolumn{3}{|c|}{ Radiation Measured $\left(\mathrm{W} / \mathrm{m}^{2}\right)$} & \\
\hline \multirow{5}{*}{$\begin{array}{l}\text { UVB } \\
(290-320 \mathrm{~nm})\end{array}$} & 2.1 & 0.1 & 0.1 & $11: 15$ & \multirow[t]{2}{*}{1.8} & \multicolumn{2}{|l|}{0.1} & \multirow[t]{2}{*}{$11: 50$} \\
\hline & 2.5 & 0.1 & 0.1 & $12: 25$ & & & & \\
\hline & 2.7 & 0.2 & 0.1 & $1: 12$ & 2.3 & \multicolumn{2}{|l|}{0.2} & $1: 10$ \\
\hline & 1.7 & 0.1 & 0.1 & $3: 38$ & \multirow[t]{2}{*}{1.0} & \multirow{2}{*}{\multicolumn{2}{|c|}{0.1}} & \multirow[t]{2}{*}{$4: 55$} \\
\hline & 1.2 & 0.1 & 0.1 & $5: 00$ & & & & \\
\hline UVA & 50.1 & 24.3 & 0.8 & $11: 15$ & \multirow[t]{2}{*}{50.1} & \multicolumn{2}{|l|}{34.1} & \multirow[t]{2}{*}{$11: 50$} \\
\hline \multirow[t]{4}{*}{$(320-400 \mathrm{~nm})$} & 53.8 & 29.8 & 1.4 & $12: 25$ & & \multirow{2}{*}{\multicolumn{2}{|c|}{26.4}} & \\
\hline & 57.1 & 34.0 & 1.0 & $1: 12$ & 49.4 & & & $1: 10$ \\
\hline & 41.8 & 25.4 & 0.7 & $3: 38$ & \multirow[t]{2}{*}{31.8} & \multicolumn{2}{|l|}{21.1} & \multirow[t]{2}{*}{$4: 55$} \\
\hline & 38.2 & 19.5 & 0.5 & 5:00 & & & & \\
\hline Photopic & 164 & 150 & 177 & $11: 15$ & 160 & 130 & & $11: 50$ \\
\hline$(400-700 \mathrm{~nm})$ & 166 & 128 & 217 & $12: 25$ & & & & \\
\hline & 163 & 142 & 172 & $1: 12$ & 157 & 111 & & $1: 10$ \\
\hline & 95 & 57 & 68 & $3: 38$ & 141 & 110 & & $4: 55$ \\
\hline & 145 & 109 & 113 & 5:00 & & & & \\
\hline Mercury Species & & & & & & & & \\
\hline Date performed & & July & 2009 & & & Septembe & 01,2009 & \\
\hline $\begin{array}{l}\text { Photoexperiment } \\
\text { exposure }\end{array}$ & full sun & no UVB & no UV & $\begin{array}{l}\text { Time of } \\
\text { Day }\end{array}$ & full sun & no UVB & no UV & Time of Day \\
\hline Spectrum & Radiat & Measure & $\left.\mathrm{W} / \mathrm{m}^{2}\right)$ & & Radiati & Measured & $\left.\mathrm{W} / \mathrm{m}^{2}\right)$ & \\
\hline UVB & 1.5 & 0.1 & 0.1 & $11: 45$ & 1.6 & 0.1 & 0.1 & $11: 25$ \\
\hline$(290-320 \mathrm{~nm})$ & 2.2 & 0.2 & 0.1 & $12: 15$ & 2.1 & 0.1 & 0.1 & 1:00 \\
\hline & 2.5 & 0.1 & 0.1 & $1: 45$ & 1.7 & 0.1 & 0.1 & $3: 00$ \\
\hline & 1.0 & 0.1 & 0.1 & $5: 00$ & 0.9 & 0.1 & 0.1 & 4:50 \\
\hline UVA & 43.9 & 25.3 & 0.7 & $11: 45$ & 44.1 & 22.9 & 0.7 & $11: 25$ \\
\hline$(320-400 \mathrm{~nm})$ & 52.7 & 37.1 & 1.1 & $12: 15$ & 48.6 & 25.1 & 0.7 & $1: 00$ \\
\hline & 54.4 & 28.3 & 1.4 & $1: 45$ & 44.0 & 24.7 & 0.6 & $3: 00$ \\
\hline & 40.1 & 19.7 & 0.5 & 5:00 & 30.4 & 20.4 & 0.5 & 4:50 \\
\hline Photopic & 145 & 114 & 136 & $11: 45$ & 152 & 107 & 149 & $11: 25$ \\
\hline$(400-700 \mathrm{~nm})$ & 163 & 153 & 223 & $12: 15$ & 159 & 104 & 141 & $1: 00$ \\
\hline & 156 & 134 & 248 & $1: 45$ & 146 & 111 & 131 & $3: 00$ \\
\hline & 141 & 95 & 131 & $5: 00$ & 140 & 109 & 118 & $4: 50$ \\
\hline
\end{tabular}

Note 1: Radiometer readings at a given time were taken in the absence of (perceptible) cloud cover and in rapid succession for the most accurate comparison possbile. 
Table 3.2. Isotopic Data for $\mathrm{Hg}(\mathrm{II})$ aqueous photo-reduction

\begin{tabular}{|c|c|c|c|c|c|c|c|c|c|c|c|c|c|c|c|c|c|c|c|c|c|c|}
\hline sample name & $\begin{array}{c}f_{R} \\
\text { subst }\end{array}$ & $\begin{array}{c}\mathrm{MS} \\
\mathrm{n}\end{array}$ & $\begin{array}{c}\text { ave } \\
\delta^{204} \mathrm{Hg} \\
(\%))\end{array}$ & 2SE & $\begin{array}{c}\text { ave } \\
\delta^{202} \mathrm{Hg} \\
(\%)\end{array}$ & $2 S E$ & $\begin{array}{c}\text { ave } \\
\delta^{201} \mathrm{Hg} \\
(\%)\end{array}$ & 2SE & $\begin{array}{c}\text { ave } \\
\delta^{200} \mathrm{Hg} \\
(\%)\end{array}$ & $2 S E$ & $\begin{array}{c}\text { ave } \\
\delta^{199} \mathrm{Hg} \\
(\%)\end{array}$ & 2SE & $\begin{array}{c}\text { ave } \\
\delta^{198} \mathrm{Hg} \\
(\%)\end{array}$ & 2SE & $\begin{array}{c}\text { Avg } \\
\Delta^{204} \mathrm{Hg} \\
(\%)\end{array}$ & $2 S E$ & $\begin{array}{c}\text { Ave } \\
\Delta^{201} \mathrm{Hg} \\
(\%)\end{array}$ & 2SE & $\begin{array}{c}\text { Avg } \\
\Delta^{200} \mathrm{Hg} \\
(\%)\end{array}$ & 2SE & $\begin{array}{c}\text { Avg } \\
\Delta^{199} \mathrm{Hg} \\
(\%)\end{array}$ & 2SE \\
\hline \multicolumn{23}{|c|}{ Hg(II) July full sun } \\
\hline Ph30 R0 & 00 & 2 & -1.00 & 0.19 & -0.67 & 0.17 & -0.50 & 0.10 & -0.42 & 0.14 & -0.20 & 0.12 & -1.04 & 4.06 & 0.00 & 0.07 & 0.01 & 0.03 & -0.08 & 0.23 & -0.03 & 0.16 \\
\hline Ph30 R1 & 1.00 & 2 & \begin{tabular}{l|}
-0.92 \\
\end{tabular} & 0.04 & -0.60 & 0.01 & -0.46 & 0.04 & -0.39 & 0.14 & -0.19 & 0.11 & -0.16 & 0.68 & \begin{tabular}{|c|}
-0.03 \\
\end{tabular} & 0.03 & -0.01 & 0.04 & -0.09 & 0.14 & -0.04 & 0.11 \\
\hline Ph30 R3 & 0.79 & 2 & -0.49 & 0.03 & -0.27 & 0.02 & 0.00 & 0.05 & -0.12 & 0.01 & 0.15 & 0.05 & -2.03 & 2.49 & -0.08 & 0.05 & 0.21 & 0.06 & 0.02 & 0.01 & 0.22 & 0.05 \\
\hline Ph30 R4 & 0.64 & 2 & -0.19 & 0.08 & -0.12 & 0.05 & 0.43 & 0.04 & -0.10 & 0.02 & 0.50 & 0.04 & -1.01 & 0.02 & \begin{tabular}{|c|}
-0.01 \\
\end{tabular} & 0.01 & 0.52 & 0.00 & -0.05 & 0.01 & 0.53 & 0.06 \\
\hline Ph30 R5 & 0.27 & 2 & 0.36 & 0.04 & 0.21 & 0.03 & 1.97 & 0.02 & 0.14 & 0.09 & 1.89 & 0.06 & 0.40 & 1.64 & 0.04 & 0.01 & 1.81 & 0.00 & 0.04 & 0.11 & 1.84 & 0.07 \\
\hline Ph30 R6 & 0.18 & 2 & 1.28 & 0.13 & 0.87 & 0.09 & 3.01 & 0.06 & 0.43 & 0.15 & 2.64 & 0.07 & -0.62 & 1.55 & -0.02 & 0.00 & 2.35 & 0.00 & -0.01 & 0.19 & 2.42 & 0.09 \\
\hline & & & & & & & & & & & & & & & & & & & & & & \\
\hline \multicolumn{23}{|l|}{ Hg(II) July no U } \\
\hline Ph31 R0 & 1 & 2 & -1.04 & 0.06 & -0.69 & 0.06 & -0.55 & 0.08 & -0.23 & 0.06 & -0.12 & 0.03 & -0.36 & 0.01 & 0.00 & 0.03 & -0.03 & 0.04 & 0.11 & 0.09 & 0.06 & 0.05 \\
\hline Ph31 R1 & 1.00 & 2 & -1.02 & 0.01 & -0.68 & 0.02 & -0.54 & 0.04 & -0.35 & 0.27 & -0.15 & 0.22 & -1.17 & 0.55 & 0.00 & 0.02 & -0.03 & 0.03 & 0.00 & 0.26 & 0.02 & 0.22 \\
\hline Ph31 R3 & 0.78 & 2 & -0.41 & 0.09 & -0.26 & 0.02 & -0.07 & 0.06 & -0.20 & 0.02 & 0.04 & 0.05 & -0.74 & 1.03 & -0.02 & 0.06 & 0.12 & 0.04 & -0.06 & 0.03 & 0.11 & 0.04 \\
\hline Ph31 R5 & 0.40 & 2 & 0.46 & 0.21 & 0.32 & 0.16 & 0.87 & 0.15 & 0.32 & 0.25 & 0.79 & 0.10 & -0.66 & 2.11 & -0.02 & 0.03 & 0.63 & 0.03 & 0.16 & 0.33 & 0.71 & 0.14 \\
\hline Ph31 R6 & 0.26 & 2 & 1.23 & 0.16 & 0.81 & 0.05 & 1.73 & 0.09 & 0.25 & 0.28 & 1.26 & 0.10 & 1.38 & 1.43 & 0.02 & 0.09 & 1.12 & 0.05 & -0.16 & 0.31 & 1.05 & 0.11 \\
\hline Ph31 R7 & 0.23 & 2 & 1.71 & 0.18 & 1.19 & 0.08 & 1.89 & 0.04 & 0.28 & 0.31 & 1.17 & 0.22 & 0.54 & 1.40 & -0.06 & 0.05 & 1.00 & 0.02 & -0.32 & 0.35 & 0.87 & 0.24 \\
\hline & & & & & & & & & & & & & & & & & & & & & & \\
\hline \multicolumn{23}{|c|}{ Hg(II) July no UV } \\
\hline Ph32 R0 & 1 & 2 & -1.22 & 0.06 & -0.81 & 0.02 & -0.64 & 0.02 & -0.25 & 0.01 & -0.13 & 0.05 & -1.45 & 2.31 & -0.01 & 0.09 & -0.03 & 0.03 & 0.15 & 0.02 & 0.08 & 0.06 \\
\hline Ph32 R1 & 0.94 & 2 & -1.12 & 0.09 & -0.76 & 0.07 & -0.58 & 0.01 & -0.20 & 0.05 & -0.11 & 0.01 & -0.75 & 0.63 & 0.01 & 0.13 & -0.01 & 0.06 & 0.18 & 0.01 & 0.08 & 0.05 \\
\hline Ph32 R4 & 0.89 & 2 & -1.30 & 0.03 & -0.86 & 0.00 & -0.67 & 0.02 & -0.33 & 0.14 & -0.16 & 0.08 & -0.37 & 1.53 & -0.01 & 0.13 & -0.02 & 0.02 & 0.10 & 0.14 & 0.06 & 0.08 \\
\hline Ph32 R7 & 0.86 & 2 & -0.73 & 0.17 & -0.46 & 0.13 & -0.35 & 0.03 & -0.18 & 0.42 & -0.08 & 0.18 & 0.19 & 0.66 & -0.05 & 0.13 & -0.01 & 0.07 & 0.05 & 0.49 & 0.03 & 0.22 \\
\hline Ph32 R9 & 0.87 & 2 & -0.81 & 0.02 & -0.52 & 0.06 & -0.42 & 0.03 & -0.27 & 0.05 & -0.11 & 0.00 & -0.14 & 1.71 & -0.03 & 0.13 & -0.02 & 0.01 & -0.01 & 0.02 & 0.02 & 0.01 \\
\hline \multicolumn{23}{|c|}{$\mathrm{Hg}$ (II) Septembe } \\
\hline Ph44 R0 & 1 & 2 & -0.94 & 0.12 & -0.66 & 0.12 & -0.50 & 0.07 & -0.31 & 0.10 & -0.15 & 0.02 & -0.56 & 2.59 & 0.04 & 0.06 & -0.01 & 0.02 & 0.02 & 0.04 & 0.02 & 0.01 \\
\hline Ph44 R2 & 0.66 & 2 & -0.11 & 0.05 & -0.09 & 0.01 & 0.17 & 0.03 & -0.05 & 0.01 & 0.22 & 0.03 & 0.85 & 1.04 & 0.03 & 0.06 & 0.24 & 0.02 & 0.00 & 0.01 & 0.24 & 0.02 \\
\hline Ph44 R3 & 0.52 & 2 & 0.23 & 0.13 & 0.12 & 0.09 & 0.55 & 0.05 & 0.05 & 0.01 & 0.50 & 0.01 & 0.79 & 0.07 & 0.05 & 0.00 & 0.46 & 0.01 & -0.01 & 0.04 & 0.47 & 0.04 \\
\hline Ph44 R5 & 0.38 & 2 & 0.98 & 0.04 & 0.67 & 0.05 & 1.25 & 0.02 & 0.35 & 0.01 & 0.91 & 0.00 & 1.37 & 2.94 & -0.03 & 0.03 & 0.74 & 0.02 & 0.01 & 0.02 & 0.74 & 0.01 \\
\hline Ph44 R7 & 0.32 & 2 & 1.72 & 0.16 & 1.14 & 0.06 & 1.72 & 0.08 & 0.54 & 0.01 & 1.09 & 0.03 & 2.46 & 3.30 & 0.02 & 0.06 & 0.86 & 0.03 & -0.04 & 0.02 & 0.81 & 0.01 \\
\hline Ph44 R9 & 0.31 & 2 & 2.01 & 0.01 & 1.37 & 0.06 & 1.72 & 0.03 & 0.67 & 0.01 & 1.03 & 0.01 & 0.87 & 0.52 & -0.03 & 0.08 & 0.69 & 0.01 & -0.02 & 0.04 & 0.68 & 0.03 \\
\hline
\end{tabular}

Note 1: In graphs and calculations, 2SE of the sample replicates are used unless they are smaller than the 2SD of the secondary standard (UM-Almadén). In cases where 2SE of the sample is smaller (for both MDF and MIF) the 2SD of UM-Almadén is used (italicized entries).

Note 2: All $\mathrm{Hg}$ (II) photo-reduction experiments were carried out in $2 \mathrm{mg} / \mathrm{l}$ of Suwannee River Fulvic Acid Standard. Initial Hg2+(RO) concentrations in the reservoirs were all approximately $30 \mu \mathrm{g} / \mathrm{l}$. Specific $\mathrm{Hg}$ RO concentrations for each experiment were $32.2 \mu \mathrm{g} / \mathrm{I}$ for the $\mathrm{Hg}$ (II) July full sun experiment, $31.2 \mu \mathrm{g} / \mathrm{l}$ for the $\mathrm{Hg}$ (II) July no UVB experiment, $30.3 \mu \mathrm{g} / \mathrm{I}$ for the $\mathrm{Hg}$ (II) July no UV experiment, $31.4 \mu \mathrm{g} / \mathrm{I}$ for $\mathrm{Hg}$ (II) September full sun experiment, $28.8 \mu \mathrm{g} / \mathrm{I}$ for the Hg(II) September no UVB experiment, and $28.9 \mu \mathrm{g} / \mathrm{I}$ for the $\mathrm{Hg}(\mathrm{II})$ September no UV experiment. 
Table 3.2 continued

\begin{tabular}{|c|c|c|c|c|c|c|c|c|c|c|c|c|c|c|c|c|c|c|c|c|c|c|}
\hline sample name & $\begin{array}{c}f_{R} \\
\text { subst }\end{array}$ & $\begin{array}{c}\text { MS } \\
n\end{array}$ & $\begin{array}{c}\text { ave } \\
\delta^{204} \mathrm{Hg} \\
(\% \circ)\end{array}$ & 2SE & \begin{tabular}{|c|} 
ave \\
$\delta^{202} \mathrm{Hg}$ \\
$(\%)$
\end{tabular} & 2SE & $\begin{array}{c}\text { ave } \\
\delta^{201} \mathrm{Hg} \\
(\%)\end{array}$ & 2SE & $\begin{array}{c}\text { ave } \\
\delta^{200} \mathrm{Hg} \\
(\%)\end{array}$ & 2SE & $\begin{array}{c}\text { ave } \\
\delta^{199} \mathrm{Hg} \\
(\%)\end{array}$ & $2 \mathrm{SE}$ & \begin{tabular}{|c|} 
ave \\
$\delta^{198} \mathrm{Hg}$ \\
$(\%)$
\end{tabular} & $2 \mathrm{SE}$ & $\begin{array}{c}\text { Avg } \\
\Delta^{204} \mathrm{Hg} \\
(\% \circ)\end{array}$ & $2 \mathrm{SE}$ & $\begin{array}{c}\text { Ave } \\
\Delta^{201} \mathrm{Hg} \\
(\%)\end{array}$ & 2SE & $\begin{array}{c}\text { Avg } \\
\Delta^{200} \mathrm{Hg} \\
(\%)\end{array}$ & $2 S E$ & $\begin{array}{c}\text { Avg } \\
\Delta^{199} \mathrm{Hg} \\
(\%)\end{array}$ & 2SE \\
\hline \multicolumn{23}{|l|}{$\mathrm{Hg}$ (II) September no UVB } \\
\hline Ph46 R0 & 1 & 2 & \begin{tabular}{|l|}
-1.17 \\
\end{tabular} & 0.08 & -0.74 & 0.02 & -0.59 & 0.04 & -0.40 & 0.06 & -0.20 & 0.01 & -0.51 & 3.22 & -0.07 & 0.05 & -0.03 & 0.02 & -0.03 & 0.07 & -0.01 & 0.02 \\
\hline Ph46 R2 & 0.77 & 2 & \begin{tabular}{|l|}
-0.48 \\
\end{tabular} & 0.06 & -0.20 & 0.11 & -0.10 & 0.06 & -0.13 & 0.05 & 0.04 & 0.06 & 0.04 & 0.89 & -0.18 & 0.22 & 0.05 & 0.14 & -0.03 & 0.01 & 0.10 & 0.09 \\
\hline Ph46 R3 & 0.65 & 2 & 0.15 & 0.11 & 0.17 & 0.01 & 0.32 & 0.07 & 0.08 & 0.01 & 0.24 & 0.04 & 1.36 & 0.26 & -0.11 & 0.13 & 0.19 & 0.08 & -0.01 & 0.02 & 0.20 & 0.04 \\
\hline Ph46 R5 & 0.52 & 2 & 0.65 & 0.06 & 0.45 & 0.06 & 0.72 & 0.02 & 0.24 & 0.09 & 0.47 & 0.03 & 0.60 & 0.99 & -0.03 & 0.15 & 0.38 & 0.02 & 0.01 & 0.06 & 0.36 & 0.02 \\
\hline Ph46 R7 & 0.42 & 2 & 1.18 & 0.01 & 0.79 & 0.06 & 1.08 & 0.06 & 0.38 & 0.08 & 0.64 & 0.07 & \begin{tabular}{|l|}
-0.98 \\
\end{tabular} & 1.93 & 0.01 & 0.08 & 0.48 & 0.02 & -0.01 & 0.05 & 0.44 & 0.05 \\
\hline \multirow[t]{2}{*}{ Ph46 R9 } & 0.55 & 2 & 0.43 & 0.19 & 0.26 & 0.03 & 0.47 & 0.04 & 0.13 & 0.08 & 0.28 & 0.00 & \begin{tabular}{|l|}
-0.49 \\
\end{tabular} & 0.16 & 0.04 & 0.23 & 0.28 & 0.06 & 0.00 & 0.09 & 0.22 & 0.01 \\
\hline & & & & & & & & & & & & & & & & & & & & & & \\
\hline \multicolumn{23}{|l|}{ Hg(II) September no UV } \\
\hline Ph45 R0 & 1 & 2 & -0.93 & 0.04 & -0.61 & 0.02 & -0.41 & 0.04 & -0.30 & 0.05 & -0.08 & 0.00 & -1.41 & 1.06 & -0.02 & 0.01 & 0.05 & 0.03 & 0.00 & 0.04 & 0.08 & 0.01 \\
\hline Ph45 R2 & 0.85 & 2 & -0.59 & 0.18 & -0.39 & 0.10 & -0.23 & 0.12 & -0.20 & 0.11 & -0.01 & 0.06 & 0.59 & 0.38 & -0.01 & 0.03 & 0.07 & 0.04 & 0.00 & 0.06 & 0.09 & 0.04 \\
\hline Ph45 R3 & 0.75 & 2 & -0.18 & 0.23 & -0.15 & 0.13 & 0.06 & 0.09 & -0.08 & 0.10 & 0.14 & 0.07 & -0.08 & 1.84 & 0.04 & 0.04 & 0.17 & 0.00 & 0.00 & 0.04 & 0.18 & 0.03 \\
\hline Ph45 R5 & 0.62 & 2 & 0.26 & 0.15 & 0.19 & 0.03 & 0.41 & 0.09 & 0.08 & 0.03 & 0.37 & 0.04 & -1.00 & 0.46 & -0.02 & 0.19 & 0.27 & 0.11 & -0.01 & 0.05 & 0.32 & 0.05 \\
\hline Ph45 R7 & 0.55 & 2 & 0.30 & 0.03 & 0.19 & 0.00 & 0.48 & 0.00 & 0.08 & 0.04 & 0.41 & 0.00 & \begin{tabular}{|l|}
-0.41 \\
\end{tabular} & 1.28 & 0.02 & 0.03 & 0.34 & 0.01 & -0.01 & 0.04 & 0.36 & 0.01 \\
\hline \multirow[t]{2}{*}{ Ph45 R9 } & 0.59 & 2 & 0.10 & 0.07 & 0.03 & 0.02 & 0.20 & 0.05 & 0.02 & 0.02 & 0.19 & 0.03 & \begin{tabular}{|l|}
1.01 \\
\end{tabular} & 0.46 & 0.05 & 0.03 & 0.18 & 0.06 & 0.01 & 0.01 & 0.18 & 0.03 \\
\hline & & & & & & & & & & & & & & & & & & & & & & \\
\hline \multicolumn{23}{|c|}{ Hg(II) Dark Control 2 Abiotic reduction with Suwannee R FAS sealed bottle no sparging } \\
\hline PDR4 R0 & 1.00 & 2 & \begin{tabular}{|l|}
-0.87 \\
\end{tabular} & 0.01 & \begin{tabular}{|l|}
-0.59 \\
\end{tabular} & 0.06 & -0.49 & 0.09 & -0.30 & 0.02 & -0.14 & 0.04 & -0.08 & 2.06 & 0.01 & 0.08 & -0.05 & 0.04 & -0.01 & 0.02 & 0.01 & 0.03 \\
\hline PDR4 R1 & 0.82 & 2 & -0.84 & 0.02 & \begin{tabular}{|l|}
-0.58 \\
\end{tabular} & 0.02 & -0.48 & 0.01 & -0.33 & 0.04 & -0.17 & 0.04 & \begin{tabular}{|l|}
-0.96 \\
\end{tabular} & 0.72 & 0.02 & 0.00 & -0.05 & 0.02 & -0.04 & 0.04 & -0.02 & 0.04 \\
\hline \multirow[t]{2}{*}{ PDR4 R3 } & 0.61 & 2 & -0.59 & 0.01 & \begin{tabular}{|l|}
-0.39 \\
\end{tabular} & 0.03 & -0.33 & 0.02 & -0.19 & 0.04 & -0.14 & 0.03 & \begin{tabular}{|l|}
-0.12 \\
\end{tabular} & 2.40 & -0.01 & 0.05 & -0.04 & 0.04 & 0.00 & 0.06 & -0.04 & 0.04 \\
\hline & & & & & & & & & & & & & & & & & & & & & & \\
\hline sample name & $\begin{array}{c}f_{R} \\
\text { subst }\end{array}$ & $\begin{array}{c}\text { MS } \\
\mathrm{n}\end{array}$ & \begin{tabular}{|c|} 
ave \\
$\delta^{204} \mathrm{Hg}$ \\
$(\%)$
\end{tabular} & $2 \mathrm{SE}$ & \begin{tabular}{|c|} 
ave \\
$\delta^{202} \mathrm{Hg}$ \\
$(\%))$
\end{tabular} & 2SE & \begin{tabular}{|c|} 
ave \\
$\delta^{201} \mathrm{Hg}$ \\
$(\% \circ)$
\end{tabular} & $2 \mathrm{SE}$ & \begin{tabular}{|c|} 
ave \\
$\delta^{200} \mathrm{Hg}$ \\
$(\% \%)$
\end{tabular} & 2SE & \begin{tabular}{|c|} 
ave \\
$\delta^{199} \mathrm{Hg}$ \\
$(\%)$
\end{tabular} & 2SE & \begin{tabular}{|c|} 
ave \\
$\delta^{198} \mathrm{Hg}$ \\
$(\%)$
\end{tabular} & $2 \mathrm{SE}$ & \begin{tabular}{|c|} 
Avg \\
$\Delta^{204} \mathrm{Hg}$ \\
$(\%)$
\end{tabular} & 2SE & \begin{tabular}{|c|} 
Ave \\
$\Delta^{201} \mathrm{Hg}$ \\
$(\%)$
\end{tabular} & 2SE & $\begin{array}{c}\text { Avg } \\
\Delta^{200} \mathrm{Hg} \\
(\%)\end{array}$ & 2SE & \begin{tabular}{|c} 
Avg \\
$\Delta^{199} \mathrm{Hg}$ \\
$(\%)$
\end{tabular} & 2SE \\
\hline \multicolumn{23}{|l|}{ Bracketing Standard } \\
\hline \multirow[t]{2}{*}{ NIST 3133 all sessions } & & & -0.02 & 0.13 & -0.02 & 0.09 & -0.02 & 0.09 & 0.01 & 0.16 & 0.00 & 0.10 & -0.13 & 2.75 & 0.00 & 0.10 & 0.00 & 0.05 & 0.02 & 0.15 & 0.00 & 0.10 \\
\hline & & & & & & & & & & & & & & & & & & & & & & \\
\hline \multicolumn{23}{|l|}{ External Standard } \\
\hline UM-Amadén July + Control & & 12 & -0.89 & 0.17 & -0.58 & 0.13 & -0.49 & 0.11 & -0.27 & 0.17 & -0.14 & 0.08 & -0.28 & 2.09 & -0.03 & 0.11 & -0.06 & 0.05 & 0.02 & 0.17 & 0.00 & 0.07 \\
\hline UM-Amadén September Expts & & 20 & -0.87 & 0.15 & -0.58 & 0.09 & -0.46 & 0.08 & -0.29 & 0.08 & -0.17 & 0.08 & -0.23 & 2.96 & 0.00 & 0.12 & -0.02 & 0.05 & 0.00 & 0.06 & -0.02 & 0.07 \\
\hline
\end{tabular}

Note 1: In graphs and calculations, 2SE of the sample replicates are used unless they are smaller than the 2SD of the secondary standard (UM-Almadén). In cases where 2SE of the sample is smaller (for both MDF and MIF) the 2SD of UM-Almadén is used (italicized entries).

Note 2: All $\mathrm{Hg}(\mathrm{II})$ photo-reduction experiments were carried out in $2 \mathrm{mg} / \mathrm{l}$ of Suwannee River Fulvic Acid Standard. Initial Hg2+(RO) concentrations in the reservoirs

were all approximately $30 \mu \mathrm{g} / \mathrm{l}$. Specific $\mathrm{Hg}$ RO concentrations for each experiment were $32.2 \mu \mathrm{g} / \mathrm{I}$ for the $\mathrm{Hg}$ (II) July full sun experiment, $31.2 \mu \mathrm{g} / \mathrm{I} \mathrm{for} \mathrm{the} \mathrm{Hg}$ (II) July no UVB experiment, $30.3 \mu \mathrm{g} / \mathrm{I}$ for the $\mathrm{Hg}$ (II) July no UV experiment, $31.4 \mu \mathrm{g} / \mathrm{I}$ for $\mathrm{Hg}$ (II) September full sun experiment, $28.8 \mu \mathrm{g} / \mathrm{I}$ for the Hg(II) September no UVB

experiment, and $28.9 \mu \mathrm{g} / \mathrm{I}$ for the $\mathrm{Hg}(\mathrm{II})$ September no UV experiment. 
Table 3.3. Isotopic Data for MMHg aqueous photo-reduction with UV filtration

\begin{tabular}{|c|c|c|c|c|c|c|c|c|c|c|c|c|c|c|c|c|c|c|c|c|c|c|}
\hline sample name & $\begin{array}{c}f_{R} \\
\text { subst }\end{array}$ & $\begin{array}{c}\mathrm{MS} \\
\mathrm{n}\end{array}$ & $\begin{array}{c}\text { ave } \\
\delta^{204} \mathrm{Hg} \\
(\%)\end{array}$ & 2SE & $\begin{array}{c}\text { ave } \\
\delta^{202} \mathrm{Hg} \\
(\%))\end{array}$ & 2SE & $\begin{array}{c}\text { ave } \\
\delta^{201} \mathrm{Hg} \\
(\%)\end{array}$ & 2SE & $\begin{array}{c}\text { ave } \\
\delta^{200} \mathrm{Hg} \\
(\%))\end{array}$ & 2SE & $\begin{array}{c}\text { ave } \\
\delta^{199} \mathrm{Hg} \\
(\%)\end{array}$ & 2SE & $\begin{array}{c}\text { ave } \\
\delta^{198} \mathrm{Hg} \\
(\%)\end{array}$ & 2SE & $\begin{array}{c}\text { Avg } \\
\Delta^{204} \mathrm{Hg} \\
(\%)\end{array}$ & 2SE & $\begin{array}{c}\text { Ave } \\
\Delta^{201} \mathrm{Hg} \\
(\%))\end{array}$ & $2 \mathrm{SE}$ & $\begin{array}{c}\mathrm{Avg} \\
\Delta^{200} \mathrm{Hg} \\
(\%)\end{array}$ & $2 \mathrm{SE}$ & $\begin{array}{c}\text { Avg } \\
\Delta^{199} \mathrm{Hg} \\
(\%)\end{array}$ & 2SE \\
\hline \multicolumn{23}{|c|}{ MMHg July full sun } \\
\hline Ph25 R0 & 1.00 & 2 & -1.74 & 0.03 & -1.14 & 0.10 & -0.81 & 0.05 & -0.58 & 0.11 & -0.21 & 0.03 & -0.57 & 0.83 & -0.04 & 0.11 & 0.05 & 0.02 & 0.00 & 0.16 & 0.08 & 0.05 \\
\hline Ph25 R1 & 0.94 & 2 & -1.73 & 0.05 & -1.12 & 0.01 & -0.84 & 0.02 & -0.70 & 0.13 & -0.28 & 0.01 & 0.29 & 2.74 & -0.06 & 0.07 & 0.00 & 0.01 & -0.14 & 0.14 & 0.00 & 0.02 \\
\hline Ph25 R3 & 0.90 & 2 & -1.60 & 0.17 & -1.04 & 0.14 & -0.68 & 0.14 & -0.66 & 0.05 & -0.19 & 0.04 & 0.72 & 1.31 & -0.05 & 0.04 & 0.11 & 0.04 & -0.14 & 0.12 & 0.08 & 0.01 \\
\hline Ph25 R6 & 0.83 & 2 & -1.57 & 0.01 & -1.00 & 0.11 & -0.45 & 0.06 & -0.50 & 0.06 & 0.18 & 0.09 & -1.03 & 0.33 & -0.07 & 0.17 & 0.30 & 0.02 & 0.00 & 0.00 & 0.44 & 0.06 \\
\hline Ph25 R7 & 0.79 & 2 & -1.31 & 0.14 & -0.84 & 0.09 & -0.24 & 0.02 & -0.44 & 0.07 & 0.24 & 0.00 & -2.16 & 2.99 & -0.06 & 0.02 & 0.39 & 0.04 & -0.02 & 0.03 & 0.46 & 0.03 \\
\hline \multirow[t]{2}{*}{ Ph25 R9 } & 0.81 & 2 & -1.31 & 0.13 & -0.86 & 0.05 & -0.21 & 0.06 & -0.45 & 0.10 & 0.33 & 0.09 & -0.16 & 1.88 & -0.02 & 0.06 & 0.44 & 0.03 & -0.02 & 0.12 & 0.55 & 0.10 \\
\hline & & & & & & & & & & & & & & & & & & & & & & \\
\hline \multicolumn{23}{|c|}{ MMHg July no UVB } \\
\hline Ph28 R0 & 1.00 & 2 & -1.77 & 0.08 & -1.20 & 0.04 & -0.87 & 0.04 & -0.46 & 0.06 & -0.15 & 0.04 & 0.02 & 0.90 & 0.02 & 0.13 & 0.04 & 0.01 & 0.14 & 0.08 & 0.16 & 0.05 \\
\hline Ph28 R1 & 0.94 & 2 & -1.69 & 0.12 & -1.14 & 0.01 & -0.83 & 0.12 & -0.60 & 0.11 & -0.22 & 0.04 & 0.51 & 0.63 & 0.01 & 0.13 & 0.03 & 0.11 & -0.03 & 0.12 & 0.07 & 0.04 \\
\hline Ph28 R3 & 0.91 & 2 & -1.71 & 0.00 & -1.14 & 0.04 & -0.82 & 0.01 & -0.71 & 0.10 & -0.28 & 0.08 & -0.20 & 2.06 & -0.01 & 0.13 & 0.03 & 0.04 & -0.14 & 0.12 & 0.01 & 0.09 \\
\hline Ph28 R5 & 0.86 & 2 & -1.67 & 0.12 & -1.15 & 0.07 & -0.79 & 0.10 & -0.53 & 0.05 & -0.18 & 0.06 & -0.81 & 0.46 & 0.04 & 0.13 & 0.07 & 0.04 & 0.05 & 0.01 & 0.11 & 0.04 \\
\hline Ph28 R7 & 0.83 & 2 & -1.57 & 0.12 & -1.01 & 0.03 & -0.72 & 0.05 & -0.47 & 0.05 & -0.14 & 0.00 & -1.29 & 0.72 & -0.06 & 0.13 & 0.04 & 0.03 & 0.03 & 0.03 & 0.11 & 0.01 \\
\hline \multirow[t]{2}{*}{ Ph28 R8 } & 0.83 & 2 & -1.48 & 0.18 & -1.00 & 0.04 & -0.70 & 0.05 & -0.39 & 0.06 & -0.08 & 0.02 & -0.50 & 0.32 & 0.02 & 0.13 & 0.06 & 0.02 & 0.12 & 0.04 & 0.17 & 0.00 \\
\hline & & & & & & & & & & & & & & & & & & & & & & \\
\hline \multicolumn{23}{|c|}{ MMHg July no UV } \\
\hline Ph29R0 & 1 & 2 & -1.86 & 0.17 & -1.22 & 0.01 & -0.91 & 0.05 & -0.52 & 0.02 & -0.21 & 0.04 & $\mid-1.01$ & 0.19 & -0.03 & 0.15 & 0.01 & 0.04 & 0.09 & 0.03 & 0.09 & 0.04 \\
\hline Ph29 R1 & 0.94 & 2 & -1.87 & 0.02 & -1.27 & 0.08 & -0.89 & 0.07 & -0.40 & 0.18 & -0.09 & 0.05 & -3.40 & 1.73 & 0.03 & 0.10 & 0.07 & 0.01 & 0.24 & 0.22 & 0.23 & 0.07 \\
\hline Ph29 R3 & 0.91 & 2 & -1.68 & 0.00 & -1.07 & 0.10 & -0.81 & 0.04 & -0.45 & 0.01 & -0.14 & 0.02 & -0.32 & 1.16 & -0.08 & 0.15 & 0.00 & 0.11 & 0.09 & 0.07 & 0.13 & 0.01 \\
\hline Ph29 R5 & 0.83 & 2 & -1.38 & 0.14 & -0.93 & 0.11 & -0.61 & 0.09 & -0.45 & 0.16 & -0.14 & 0.13 & -1.70 & 0.93 & 0.01 & 0.01 & 0.09 & 0.01 & 0.02 & 0.11 & 0.09 & 0.10 \\
\hline Ph29 R7 & 0.78 & 2 & -1.46 & 0.11 & -0.95 & 0.10 & -0.61 & 0.04 & -0.38 & 0.12 & -0.06 & 0.10 & -1.67 & 0.41 & -0.03 & 0.03 & 0.11 & 0.04 & 0.09 & 0.17 & 0.18 & 0.12 \\
\hline \multirow[t]{2}{*}{ Ph29 R8 } & 0.79 & 2 & -1.35 & 0.06 & -0.90 & 0.02 & -0.59 & 0.03 & -0.50 & 0.03 & -0.15 & 0.02 & -1.17 & 1.33 & -0.01 & 0.02 & 0.08 & 0.02 & -0.05 & 0.02 & 0.08 & 0.02 \\
\hline \multirow{2}{*}{\multicolumn{23}{|c|}{ MMHg September full sun }} \\
\hline & & & & & & & & & & & & & & & & & & & & & & \\
\hline Ph41R0 & 1 & 2 & -1.71 & 0.14 & -1.14 & 0.04 & -0.84 & 0.03 & -0.57 & 0.06 & -0.23 & 0.01 & -1.05 & 1.88 & -0.02 & 0.07 & 0.01 & 0.00 & 0.00 & 0.04 & 0.05 & 0.00 \\
\hline Ph41 R1 & 1.00 & 2 & -1.81 & 0.07 & -1.21 & 0.17 & -0.88 & 0.14 & -0.60 & 0.07 & -0.22 & 0.05 & 0.04 & 0.76 & -0.01 & 0.19 & 0.03 & 0.01 & 0.00 & 0.01 & 0.08 & 0.00 \\
\hline Ph41 R3 & 0.98 & 2 & -1.57 & 0.02 & -1.03 & 0.06 & -0.60 & 0.11 & -0.51 & 0.01 & -0.03 & 0.01 & \begin{tabular}{|l|}
-1.09 \\
\end{tabular} & 0.29 & -0.04 & 0.11 & 0.18 & 0.04 & 0.00 & 0.03 & 0.23 & 0.02 \\
\hline Ph41 R4 & 0.93 & 2 & -1.58 & 0.10 & -1.02 & 0.09 & -0.60 & 0.03 & -0.51 & 0.07 & 0.00 & 0.02 & \begin{tabular}{|l|}
-1.71 \\
\end{tabular} & 3.55 & -0.06 & 0.03 & 0.17 & 0.02 & 0.01 & 0.02 & 0.26 & 0.00 \\
\hline Ph41 R5 & 0.91 & 2 & -1.49 & 0.07 & -0.95 & 0.04 & -0.53 & 0.02 & -0.48 & 0.01 & 0.13 & 0.02 & 0.11 & 0.39 & -0.08 & 0.02 & 0.18 & 0.01 & 0.00 & 0.01 & 0.37 & 0.00 \\
\hline Ph41 R6 & 0.92 & 2 & -1.44 & 0.01 & -0.93 & 0.05 & -0.37 & 0.04 & -0.46 & 0.05 & 0.23 & 0.00 & -2.76 & 0.13 & -0.05 & 0.07 & 0.33 & 0.00 & 0.01 & 0.03 & 0.47 & 0.01 \\
\hline
\end{tabular}

Note 1: In graphs and calculations, 2SE of the sample replicates are used unless they are smaller than the 2SD of the secondary standard (UM-Almadén). In cases where 2SE of the sample is smaller (for both MDF and MIF) the 2SD of UM-Almadén is used (italicized entries).

Note 2: All MeHg photo-reduction experiments were carried out in $2 \mathrm{mg} / \mathrm{l}$ of Suwannee River Fulvic Acid Standard. Initial Hg (R0) concentrations in the reservoirs were all approximately $25 \mu \mathrm{g} / \mathrm{l}$. Specific $\mathrm{Hg}$ RO concentrations for each experiment were $25.0 \mu \mathrm{g} / \mathrm{l}$ for the MeHg July full sun experiment, $25.8 \mu \mathrm{g} / \mathrm{l}$ for the MeHg July no UVB experiment, $26.0 \mu \mathrm{g} / \mathrm{I}$ for the MeHg July no UV experiment, $24.5 \mu \mathrm{g} / \mathrm{l}$ for MeHg September full sun experiment, $24.0 \mu \mathrm{g} / \mathrm{l}$ for the MeHg September no UVB experiment, and $23.0 \mu \mathrm{g} / \mathrm{l}$ for the MeHg September no UV experiment. 
Table 3.3 continued

\begin{tabular}{|c|c|c|c|c|c|c|c|c|c|c|c|c|c|c|c|c|c|c|c|c|c|c|}
\hline sample name & $\begin{array}{c}f_{R} \\
\text { subst }\end{array}$ & $\begin{array}{c}\mathrm{MS} \\
\mathrm{n}\end{array}$ & $\begin{array}{c}\text { ave } \\
\delta^{204} \mathrm{Hg} \\
(\%)\end{array}$ & 2SE & $\begin{array}{c}\text { ave } \\
\delta^{202} \mathrm{Hg} \\
(\%)\end{array}$ & 2SE & $\begin{array}{c}\text { ave } \\
\delta^{201} \mathrm{Hg} \\
(\%)\end{array}$ & 2SE & $\begin{array}{c}\text { ave } \\
\delta^{200} \mathrm{Hg} \\
(\%)\end{array}$ & 2SE & $\begin{array}{c}\text { ave } \\
\delta^{199} \mathrm{Hg} \\
(\%)\end{array}$ & 2SE & $\begin{array}{c}\text { ave } \\
\delta^{198} \mathrm{Hg} \\
(\%)\end{array}$ & 2SE & $\begin{array}{c}\text { Avg } \\
\Delta^{204} \mathrm{Hg} \\
(\%)\end{array}$ & 2SE & $\begin{array}{c}\text { Ave } \\
\Delta^{201} \mathrm{Hg} \\
(\%)\end{array}$ & 2SE & $\begin{array}{c}\text { Avg } \\
\Delta^{200} \mathrm{Hg} \\
(\%)\end{array}$ & 2SE & $\begin{array}{c}\text { Avg } \\
\Delta^{199} \mathrm{Hg} \\
(\%)\end{array}$ & 2SE \\
\hline \multicolumn{23}{|c|}{ MMHg September no UVB } \\
\hline Ph42 R0 & 1.00 & 2 & -1.73 & 0.07 & $\mid-1.16$ & 0.06 & -0.84 & 0.05 & -0.60 & 0.04 & -0.23 & 0.05 & \begin{tabular}{c|c|c|}
-0.61 \\
\end{tabular} & 2.63 & 0.00 & 0.02 & 0.03 & 0.00 & -0.02 & 0.01 & 0.06 & 0.07 \\
\hline Ph42 R1 & 1.01 & $\frac{4}{2}$ & -1.77 & 0.10 & -1.19 & 0.11 & \begin{tabular}{|c|}
-0.83 \\
\end{tabular}$-20$ & \begin{tabular}{|l|l|}
0.07 \\
\end{tabular} & -0.60 & 0.03 & -0.25 & 0.01 & -0.88 & 0.33 & 0.01 & 0.07 & 0.06 & 0.02 & 0.00 & \begin{tabular}{|l|l|}
0.03 \\
\end{tabular} & 0.05 & \begin{tabular}{|l|l|}
0.04 & \\
\end{tabular} \\
\hline Ph42 R2 & 0.97 & 2 & -1.64 & 0.03 & -1.08 & 0.05 & -0.74 & 0.04 & -0.52 & 0.01 & -0.13 & 0.06 & -1.25 & 2.73 & -0.03 & 0.11 & 0.08 & 0.00 & 0.03 & \begin{tabular}{|l|l|}
0.01 \\
\end{tabular} & 0.14 & \begin{tabular}{|l|l|}
0.04 & \\
\end{tabular} \\
\hline Ph42 R4 & 0.96 & 2 & -1.07 & 0.03 & -0.74 & 0.14 & -0.38 & 0.18 & -0.38 & 0.23 & 0.06 & 0.18 & -2.30 & 4.52 & 0.03 & 0.18 & 0.18 & 0.08 & 0.00 & 0.16 & 0.24 & \begin{tabular}{|l|}
0.14 \\
\end{tabular} \\
\hline Ph42R & 0.89 & 2 & -1.56 & 0.07 & -1.03 & 0.05 & -0.64 & 0.00 & -0.51 & 0.01 & -0.07 & 0.04 & 2.09 & 1.38 & -0.02 & 0.00 & 0.14 & 0.04 & 0.01 & 0.03 & 0.19 & 0.05 \\
\hline \multirow[t]{3}{*}{ Ph42 R6 } & 0.89 & 2 & -1.30 & 0.08 & -0.87 & 0.06 & -0.50 & \begin{tabular}{|l|}
0.01 \\
\end{tabular} & -0.43 & 0.02 & 0.00 & 0.02 & 0.41 & 0.96 & 0.01 & 0.00 & 0.16 & 0.03 & 0.01 & 0.05 & 0.23 & \begin{tabular}{|l|}
0.04 \\
\end{tabular} \\
\hline & & & & & & & & & & & & & & & & & & & & & & \\
\hline \multirow{3}{*}{\multicolumn{23}{|c|}{ MMHg September no UV }} \\
\hline & & & & & & & & & & & & & & & & & & & & & & \\
\hline & & & -1.79 & 0.12 & \begin{tabular}{|l|}
-1.18 \\
\end{tabular} & 0.06 & -0.80 & 0.03 & -0.58 & 0.02 & -0.15 & 0.05 & -2.70 & 2.18 & -0.03 & 0.03 & 0.09 & 0.07 & 0.01 & 0.05 & 0.15 & 0.04 \\
\hline Ph43 R2 & 0.96 & $\frac{4}{2}$ & -1.73 & \begin{tabular}{|l|}
0.10 \\
\end{tabular} & -1.18 & 0.02 & -0.80 & \begin{tabular}{|l|}
0.10 \\
\end{tabular} & -0.57 & 0.06 & -0.21 & 0.03 & 0.24 & 1.58 & 0.03 & 0.07 & 0.08 & \begin{tabular}{|l|}
0.09 \\
\end{tabular} & 0.02 & \begin{tabular}{|l|l|}
0.05 \\
\end{tabular} & 0.08 & 0.03 \\
\hline Ph43 R3 & 0.95 & 2 & -1.66 & 0.15 & -1.11 & 0.07 & \begin{tabular}{|c|}
-0.75 \\
\end{tabular} & \begin{tabular}{|l|}
0.04 \\
\end{tabular} & -0.54 & 0.07 & -0.14 & 0.04 & -0.14 & 0.92 & 0.01 & 0.05 & 0.09 & \begin{tabular}{|l|}
0.01 \\
\end{tabular} & 0.02 & \begin{tabular}{|l|}
0.03 \\
\end{tabular} & 0.15 & \begin{tabular}{|l|l|}
0.02 \\
\end{tabular} \\
\hline Ph43 R4 & 0.95 & 2 & -1.72 & 0.04 & -1.18 & 0.02 & \begin{tabular}{|c|}
-0.83 \\
\end{tabular} & 0.03 & -0.61 & 0.05 & -0.21 & 0.05 & \begin{tabular}{|c|}
-0.31 \\
\end{tabular} & 1.53 & 0.04 & 0.01 & 0.06 & 0.01 & -0.01 & 0.04 & 0.09 & 0.04 \\
\hline Ph43 R5 & 0.96 & 2 & -1.78 & 0.04 & -1.20 & 0.10 & -0.87 & 0.10 & -0.60 & 0.07 & -0.18 & 0.11 & 0.16 & 1.33 & 0.01 & 0.18 & 0.03 & 0.03 & 0.00 & 0.03 & 0.12 & 0.09 \\
\hline \multirow[t]{2}{*}{ Ph43 R6 } & 0.96 & 2 & -1.71 & 0.00 & \begin{tabular}{|l|}
-1.14 \\
\end{tabular} & 0.06 & \begin{tabular}{|c|}
-0.79 \\
\end{tabular} & \begin{tabular}{|l|}
0.05 \\
\end{tabular} & -0.54 & 0.01 & -0.15 & 0.04 & -3.18 & 3.09 & -0.01 & \begin{tabular}{|l|}
0.09 \\
\end{tabular} & 0.07 & \begin{tabular}{|l|}
0.09 \\
\end{tabular} & 0.03 & \begin{tabular}{|l|}
0.02 \\
\end{tabular} & 0.14 & 0.05 \\
\hline & & & & & & & & & & & & & & & & & & & & & & \\
\hline & $f_{R}$ & MS & $\begin{array}{l}\text { ave } \\
\delta^{204} \mathrm{Hg}\end{array}$ & & $\begin{array}{c}\text { ave } \\
\delta^{202} \mathrm{Hg}\end{array}$ & & \begin{tabular}{|c|} 
ave \\
$\delta^{201} \mathrm{Hg}$ \\
\end{tabular} & & \begin{tabular}{c|} 
ave \\
$\delta^{200} \mathrm{Hg}$
\end{tabular} & & $\begin{array}{c}\text { ave } \\
\delta^{199} \mathrm{Hg}\end{array}$ & & $\begin{array}{c}\text { ave } \\
\delta^{198} \mathrm{Hg}\end{array}$ & & $\begin{array}{c}\text { Avg } \\
\Delta^{204} \mathrm{Hg}\end{array}$ & & \begin{tabular}{|c|} 
Ave \\
$\Delta^{201} \mathrm{Hg}$ \\
\end{tabular} & & $\begin{array}{c}\text { Avg } \\
\Delta^{200} \mathrm{Hg}\end{array}$ & & $\begin{array}{c}\text { Avg } \\
\Delta^{199} \mathrm{Hg}\end{array}$ & \\
\hline sample & & & & $2 \mathrm{SE}$ & $(\%)$ & 2SE & $(\%)$ & $2 \mathrm{SE}$ & $(\%)$ & 2SE & $(\%)$ & 2SE & $(\%)$ & 2SE & $(\%)$ & $2 \mathrm{SE}$ & $(\%)$ & $2 \mathrm{SE}$ & $(\%)$ & $2 \mathrm{SE}$ & & 2SE \\
\hline \begin{tabular}{|l} 
Bracketing Standard \\
NIST 3133 all sessions \\
\end{tabular} & & & -0.02 & 0.13 & -0.02 & 0.09 & \begin{tabular}{|c|}
-0.02 \\
\end{tabular} & 0.09 & 0.01 & 0.16 & 0.00 & 0.10 & -0.13 & 2.75 & 0.00 & 0.10 & 0.00 & 0.05 & 0.02 & 0.15 & 0.00 & 0.10 \\
\hline & & & & & & & & & & & & & & & & & & & & & & \\
\hline \multicolumn{23}{|l|}{ External Standard } \\
\hline UM-Amadén July + Cor & & 12 & -0.89 & \begin{tabular}{|l|}
0.17 \\
\end{tabular} & -0.58 & 0.13 & -0.49 & \begin{tabular}{|l|}
0.11 \\
\end{tabular} & -0.27 & 0.17 & -0.14 & 0.08 & -0.28 & 2.09 & -0.03 & 0.11 & -0.06 & 0.05 & 0.02 & 0.17 & 0.00 & 0.07 \\
\hline UM-Amadén & & 20 & -0.87 & 0.15 & -0.58 & 0.09 & \begin{tabular}{|c|}
-0.46 \\
\end{tabular} & $\overline{0.08}$ & -0.29 & 0.08 & -0.17 & 0.08 & 0.23 & 2.96 & 0.00 & 0.12 & -0.02 & 0.05 & 0.00 & 0.06 & -0.02 & \\
\hline
\end{tabular}

Note 1: In graphs and calculations, 2SE of the sample replicates are used unless they are smaller than the 2SD of the secondary standard (UM-Almadén). In cases where 2SE of the sample is smaller (for both MDF and MIF) the 2SD of UM-Almadén is used (italicized entries).

Note 2: All MeHg photo-reduction experiments were carried out in $2 \mathrm{mg} / \mathrm{l}$ of Suwannee River Fulvic Acid Standard. Initial Hg (R0) concentrations in the reservoirs were

all approximately $25 \mu \mathrm{g} / \mathrm{l}$. Specific $\mathrm{Hg} \mathrm{RO}$ concentrations for each experiment were $25.0 \mathrm{\mu g} / \mathrm{l}$ for the MeHg July full sun experiment, $25.8 \mu \mathrm{g} / \mathrm{l}$ for the MeHg July no

UVB experiment, $26.0 \mu \mathrm{g} / \mathrm{I}$ for the MeHg July no UV experiment, $24.5 \mu \mathrm{g} / \mathrm{I}$ for MeHg September full sun experiment, $24.0 \mu \mathrm{g} / \mathrm{l}$ for the MeHg September no UVB

experiment, and $23.0 \mu \mathrm{g} / \mathrm{I}$ for the MeHg September no UV experiment. 